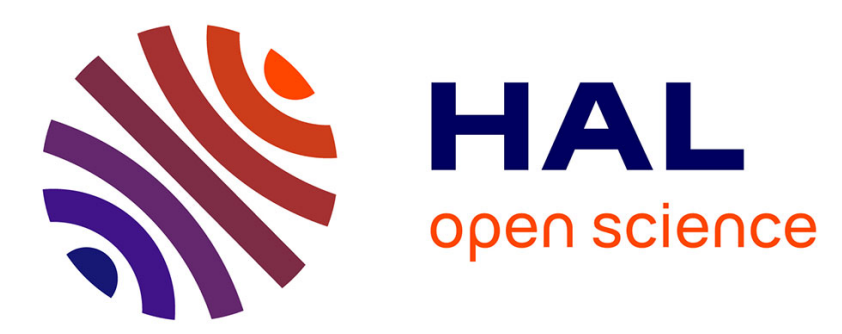

\title{
A simple and effective approach to prepare injectable macroporous calcium phosphate cement for bone repair: Syringe-foaming using a viscous hydrophilic polymeric solution
}

Jingtao Zhang, Weizhen Liu, Olivier Gauthier, Sophie Sourice, Paul Pilet, Gildas Réthoré, Khalid Khairoun, Jean-Michel Bouler, Franck Tancret, Pierre Weiss

\section{- To cite this version:}

Jingtao Zhang, Weizhen Liu, Olivier Gauthier, Sophie Sourice, Paul Pilet, et al.. A simple and effective approach to prepare injectable macroporous calcium phosphate cement for bone repair: Syringefoaming using a viscous hydrophilic polymeric solution. Acta Biomaterialia, 2016, 31, pp.326-338. 10.1016/j.actbio.2015.11.055 . hal-01723572

\section{HAL Id: hal-01723572 \\ https://hal.science/hal-01723572}

Submitted on 3 Mar 2021

HAL is a multi-disciplinary open access archive for the deposit and dissemination of scientific research documents, whether they are published or not. The documents may come from teaching and research institutions in France or abroad, or from public or private research centers.
L'archive ouverte pluridisciplinaire HAL, est destinée au dépôt et à la diffusion de documents scientifiques de niveau recherche, publiés ou non, émanant des établissements d'enseignement et de recherche français ou étrangers, des laboratoires publics ou privés. 


\section{A simple and effective approach to prepare injectable macroporous calcium phosphate cement for bone repair: syringe-foaming via viscous hydrophilic polymeric solution}

Jingtao ZHANG ${ }^{\mathrm{a}, \mathrm{b}}$, Weizhen LIU ${ }^{\mathrm{a}, \mathrm{b}}$, Olivier GAUTHIER ${ }^{\mathrm{c}}$, Sophie SOURICE ${ }^{\mathrm{a}}$, Paul PILET ${ }^{\mathrm{a}}$, Gildas RETHORE ${ }^{\mathrm{a}}$, Khalid KHAIROUN ${ }^{\text {a }}$, Jean-Michel BOULER ${ }^{\text {a }}$, Franck TANCRET ${ }^{\mathrm{b}}$, Pierre WEISS ${ }^{\text {a }}$

${ }^{a}$ Université de Nantes, INSERM UMRS 791, LIOAD, Faculté de Chirurgie Dentaire, BP 84215, 44042 Nantes Cedex 1,

France

${ }^{b}$ Université de Nantes, Polytech Nantes, Institut des Matériaux Jean Rouxel, Rue Christian Pauc, BP 50609, 44306 Nantes Cedex 3, France

${ }^{c}$ ONIRIS - Ecole Nationale Veterinaire de Nantes, Atlanpole-La Chantrerie, BP 40706, 44307 Nantes cedex 3, France *CORRESPONDING AUTHOR:

Prof. Jean-Michel BOULER

Email: Jean-Michel.Bouler@univ-nantes.fr

Prof. Franck TANCRET

Email: franck.tancret@univ-nantes.fr

Tel. : +33 (0) 240683197

Fax. : +33 (0) 240683199

Polytech Nantes (Ecole polytechnique de l'université de Nantes), Institut des Matériaux Jean Rouxel (IMN, site Chantrerie), Rue Christian Pauc, BP 50609, 44306 Nantes Cedex 3, France

\section{Graphical abstracts}


- Simple preparation

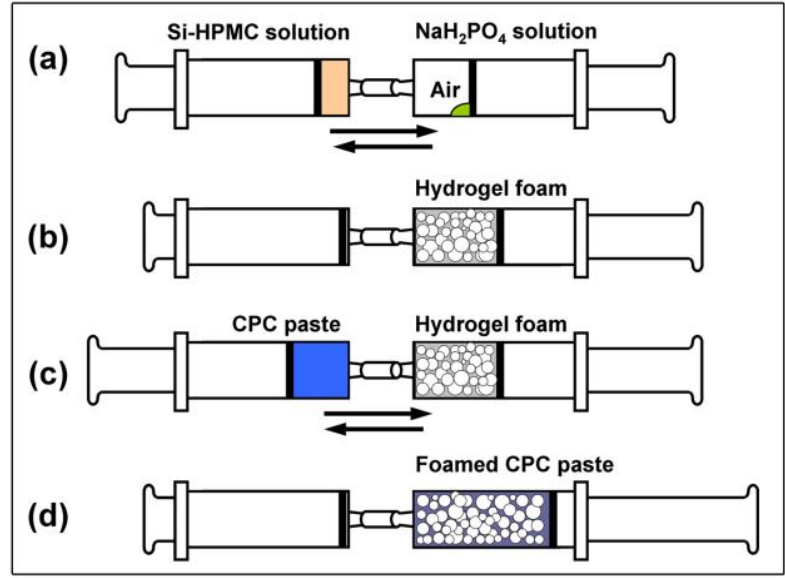

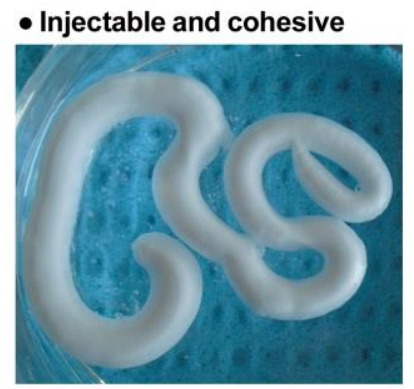

- Newly mineralized bone

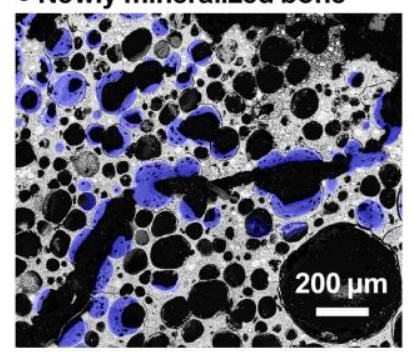

- Hierarchical macropores

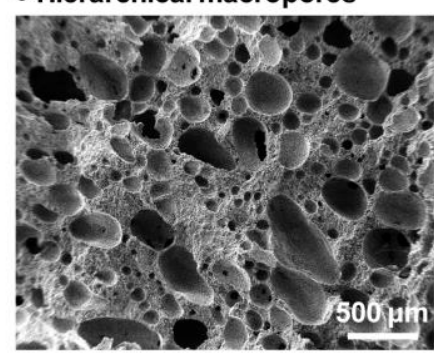

- Positive histology

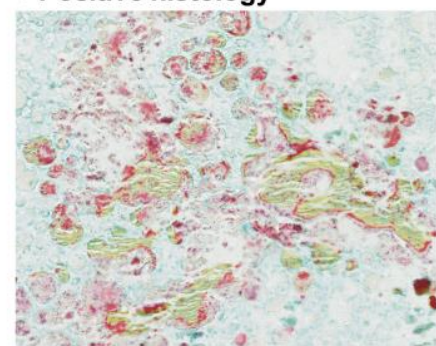

\section{Abstract}

In this study, we propose a simple and effective strategy to prepare injectable macroprous calcium phosphate cements (CPCs) by syringe-foaming via hydrophilic viscous polymeric solution, such as using silanized-hydroxypropyl methylcellulose (Si-HPMC) as a foaming agent. The Si-HPMC foamed CPCs demonstrate excellent handling properties such as injectability and cohesion. After setting the foamed CPCs possess hierarchical macropores and their mechanical properties (Young's modulus and compressive strength) are comparable to those of cancellous bone. Moreover, a preliminary in vivo study in the distal femoral sites of rabbits was conducted to evaluate the biofunctionality of this injectable macroporous CPC. The evidence of newly formed bone in the deep zone of implantation site indicates the feasibility and effectivity of this foaming strategy. Finally, the optimizing hydrogel formulation and alternative viscous hydrophilic polymers have been considered.

\section{Introduction}

Calcium phosphate cements (CPCs) are attractive as bone substitute due to their injectability, self-setting ability at physiological conditions, their higher similarity to biological apatites and higher reactivity than that of a ceramic hydroxyapatite [1-4]. Moreover, from the biological point of view, CPCs have the following excellent properties: on the one hand, they have proved to be biocompatible, bioconductive and able to be replaced by new bone [5-7]. On the other hand, they have intrinsic micropores [8] allowing nutrients and metabolic wastes to flow and transport throughout the implant site, which is beneficial to bone regeneration. 
However, not only micropores but also macropores are necessary to accelerate resorption of CPCs and bone ingrowth. The micropores are too small to ensure the migration and proliferation of bone cells as well as the angiogenesis. As a result, CPCs without macropores, especially apatitic cements given low physicochemical solubility, present a slow rate of resorption and can only be slowly replaced by new bone from periphery of the defect [9-11]. Therefore, it is imperative to introduce macropores in CPCs in order to achieve a fast resorption of CPCs and facilitate bone ingrowth not only from the periphery but also throughout the implant.

One of the challenges of introducing macropores in CPCs is to create macropores and simultaneously keep the in situ setting reaction of CPCs without disintegration in the presence of liquid medium. In this sense, the techniques used to prepare macroporous CPCs are completely different from the ones used on porous ceramics [12-16] which obtain macropores by eliminating porogenic materials during sintering and sometimes by using toxic materials. The ideal methods for preparing macroporous CPCs should fulfill the following features: first of all, the macroporous CPCs should not lose the self-setting and injectable characteristics of cement-type material. Second, the pastes of macroporous CPCs should own a good cohesion, without disintegration in contact with blood or other physiological solutions. In addition, the hardened macroporous CPCs should have a certain mechanical strength to support the structure of tissue layer. Last but not least, the additives used in macroporous CPCs should be nontoxic and biocompatible.

To date, a number of different approaches have been tried to prepare macroporous CPCs, including adding soluble porogenic agents [17, 18], gas-generating compounds [19, 20], surfactant [21], and resorbable polymers [22-26], even using three-dimensional printing [27] and solid free fabrication process [28]. However, adding a large amount of porogenic agents to insure the interconnectivity of the porosity could compromise the workability and biocompatibility of CPCs. Besides, some of the routes could only be applied on pre-set cements, thus could not be used in minimally invasive surgery; and some of the routes presented required complex processes of preparation.

Recently, a new strategy was proposed by Ginebra's group, namely mixing the cement paste or the powder phase of cement with a foam which was obtained by using a foaming agent (such as albumen [29], polysorbate 80 [30], gelatine [31] and soybean hydrogel [32]). This approach operates without affecting the in situ setting of CPCs and can obtain injectable macroporous CPCs having the possibility to be implanted via minimally invasive surgical techniques. The critical point in this approach is the selection 
of the foaming agent, which must be water soluble, nontoxic and biocompatible associated with good foaming ability and foam stability.

In our previous studies, we found that the hydroxypropyl methylcellulose (HPMC) and silanized-hydroxypropyl methylcellulose (Si-HPMC), which are biocompatible hydrophilic polymers, can not only improve the injectability and cohesion of the CPC pastes, but also enhance the resistance of CPCs to cracking $[33,34]$. Moreover, we observed increasing amount of macropores in both HPMC and Si-HPMC composite CPCs owing to the air bubbles unavoidably trapped during preparation of composite CPC pastes [refs]. Based on the above work, it could be anticipated that by using these biocompatible viscous hydrophilic polymers as foaming agents to voluntarily entrain air bubbles, we may prepare macroporous CPCs being injectable, cohesive, self-setting and with improved fracture behavior, which are critical factors for surgical applications of CPCs. Especially, Si-HPMC seems more attractive as the foaming agent because of its self-crosslinking property which endows the CPC pastes with an appealing rheological behavior at the early stage of setting and thus the ability to be used in open bone defects [ref: si-HPMC paper].

In this study, a simple and effective approach is proposed to prepare $\alpha$-tricalcium phosphate (TCP)-based macroporous apatitic CPCs through syringe-foaming using Si-HPMC as the foaming agent. The injectability, cohesion, microstructure, mechanical properties of this macroporous CPC are systematically investigated, and a preliminary in vivo study of this macroporous CPC is carried out in the distal femoral sites of rabbits.

\section{Materials and methods}

\subsection{Preparation of Si-HPMC foamed CPCs}

All of the reagents used in this study were of analytical grade and were used without further purification. $\alpha$-TCP powder and Si-HPMC solution are the two main components used to prepare Si-HPMC foamed CPCs. $\alpha$-TCP powder was synthesized by heating a stoichiometric mixture of dicalcium phosphate anhydrous (CaHPO4; Alfa Aesar, Germany) and calcium carbonate (CaCO3; VWR, $\mathrm{BDH}$, Prolabo) with a molar ratio $2: 1$ at $1360{ }^{\circ} \mathrm{C}$ for $15 \mathrm{~h}$, followed by quenching in air to room temperature. X-ray diffraction (XRD, X'pert pro, PANalytical, Netherlands) was applied to examine the phase purity of the synthesized $\alpha$-TCP powder and no other phase was observed. The $\alpha$-TCP powder was further mixed with 2 wt.\% of precipitated calcium-deficient hydroxyapatite (CDHA) to get the solid 
phase of CPCs, which was milled in a Mortar Grinder (Retsch RM100, Germany) for $1 \mathrm{~h}$ to get a fine powder. The mean particle size of the fine powder mixture was $6 \mu \mathrm{m}$, measured using laser diffraction granulometry (Beckman Coulter LS230, USA) after dispersion in ethanol in an ultrasonic bath.

Si-HPMC solution was prepared by dissolving in $\mathrm{NaOH}$ solution Si-HPMC powder whose synthetic procedure was detailed by Bourges et al. [ref], according to a method described by Fatimi et al [ref]. The $\mathrm{pH}$ value of the resulting Si-HPMC solutions was around 12.8. Si-HPMC solutions are stable in strong basic media $(\mathrm{pH}>12.1)$. When its $\mathrm{pH}$ decreases, Si-HPMC solution starts to gel, transforming into a hydrogel with a three dimensional network of Si-HPMC chains. The gelation principle of the Si-HPMC has been detailed elsewhere [ref]. In this study, a 30 wt.\% $\mathrm{NaH}_{2} \mathrm{PO}_{4}$ solution was used to initiate the gelation of the Si-HPMC, reaching a final $\mathrm{pH}$ ranging from 7 to 8 .

Table 1 and Fig. 1 illustrate respectively the formulation and the preparing process of the Si-HPMC foamed CPCs. According to the formulation in Table 1, the Si-HPMC solution and the $\mathrm{NaH}_{2} \mathrm{PO}_{4}$ solution were initially sealed in two commercial syringes (volume: $5 \mathrm{~mL}$, inner diameter: $14 \mathrm{~mm}$ and nozzle diameter: $2 \mathrm{~mm}$ ), being ready for use. Subsequently, desired volume of air was pumped into the syringe containing the $\mathrm{NaH}_{2} \mathrm{PO}_{4}$ solution (Fig.1A, Step a). Both syringes were then joined by a connector, and the solutions and air were rapidly mixed by pushing the two plungers of the syringes alternately in opposite directions for twenty seconds until a homogeneous Si-HPMC foam was formed (Fig.1A, Step b). The resultant $\mathrm{Si}$-HPMC foam was then kept in a syringe for 15 minutes of gelling time before the preparation of the foamed CPCs.

To prepare the CPC paste, the solid phase (98 wt.\% $\alpha$-TCP powder and 2 wt.\% CDHA) of CPC was manually mixed with $2.5 \mathrm{wt} \% \mathrm{Na}_{2} \mathrm{HPO}_{4}$ solution in a mortar at an L/P ratio of $0.35 \mathrm{~mL} / \mathrm{g}$ for $1 \mathrm{~min}$, and the resultant paste was packed into a syringe of $5 \mathrm{~mL}$, followed by removing the entrained air. It is worth reminding that here the $\mathrm{L} / \mathrm{P}$ ratio of 0.35 , for the $\mathrm{CPC}$ paste only, is calculated by dividing the number in column 2 of Table 1 by that in column 1, which is nevertheless different from the definition of the total $\mathrm{L} / \mathrm{P}$ of the final cement labeled in column 7.

Subsequently, the pre-prepared Si-HPMC hydrogel foam and CPC paste were rapidly mixed for 30 seconds following the same procedure used for the preparation of the Si-HPMC foam (i.e. using two syringes and a connector) until a homogeneous Si-HPMC foamed CPC paste was formed (Fig.1 A, Step c and d). 
Table 1 Formulation of Si-HPMC foamed CPC

\begin{tabular}{|c|c|c|c|c|c|c|c|}
\hline 1 & 2 & 3 & 4 & 5 & 6 & 7 & 8 \\
\hline $\begin{array}{l}\text { Powder } \\
\text { (g) }\end{array}$ & $\begin{array}{c}\mathrm{Na}_{2} \mathrm{HPO}_{4} \\
2.5 \mathrm{wt} . \% \\
(\mathrm{ml})\end{array}$ & $\begin{array}{l}\text { Si-HPMC } \\
\text { solution }^{\text {a }} \\
\quad(\mathrm{ml})\end{array}$ & $\begin{array}{c}\mathrm{NaH}_{2} \mathrm{PO}_{4} \\
30 \mathrm{wt} \% \\
(\mathrm{ml})\end{array}$ & $\begin{array}{c}\text { Hydrogel }^{b} \\
(\mathrm{ml})\end{array}$ & $\begin{array}{c}\text { Total } \\
\text { liquid } \\
\text { volume } \\
(\mathrm{ml})\end{array}$ & $\begin{array}{c}\text { Total } \\
\text { L/P ratio }\end{array}$ & $\begin{array}{c}\text { Mass } \\
\text { fraction of } \\
\text { Si-HPMC } \\
\text { in solid } \\
\text { phase }(\%)^{\mathrm{e}}\end{array}$ \\
\hline 4 & 1.40 & 0.917 & 0.083 & 1.00 & 2.40 & 0.60 & 0.9 \\
\hline 3 & 1.05 & 1.238 & 0.113 & 1.35 & 2.40 & 0.80 & 1.6 \\
\hline
\end{tabular}

a The concentration of Si-HPMC solution is $4 \% \mathrm{w} / \mathrm{v}\left(1 \% \mathrm{w} / \mathrm{v}=10 \mathrm{~g} \mathrm{l}^{-1}\right)$.

${ }^{b}$ The hydrogel is prepared by mixing Si-HPMC solution (column 3) with $\mathrm{NaH}_{2} \mathrm{PO}_{4}$ solution (column 4 ) and is used for foaming with a $\mathrm{V}_{\text {air }} / \mathrm{V}_{\text {hydrogel }}$ ratio from 0 to 2.0 .

${ }^{c}$ The total liquid volume includes the volume of $\mathrm{Na}_{2} \mathrm{HPO}_{4}$ solution in CPC paste (column 2) and the volume of hydrogel (column 5).

${ }^{\mathrm{d}}$ The total L/P ratio = total liquid volume $($ column 6$) /$ mass of powder $($ column 1$)$.

e The mass fraction of Si-HPMC in solid phase is the proportion of Si-HPMC polymer in the final cement without taking account of water. 

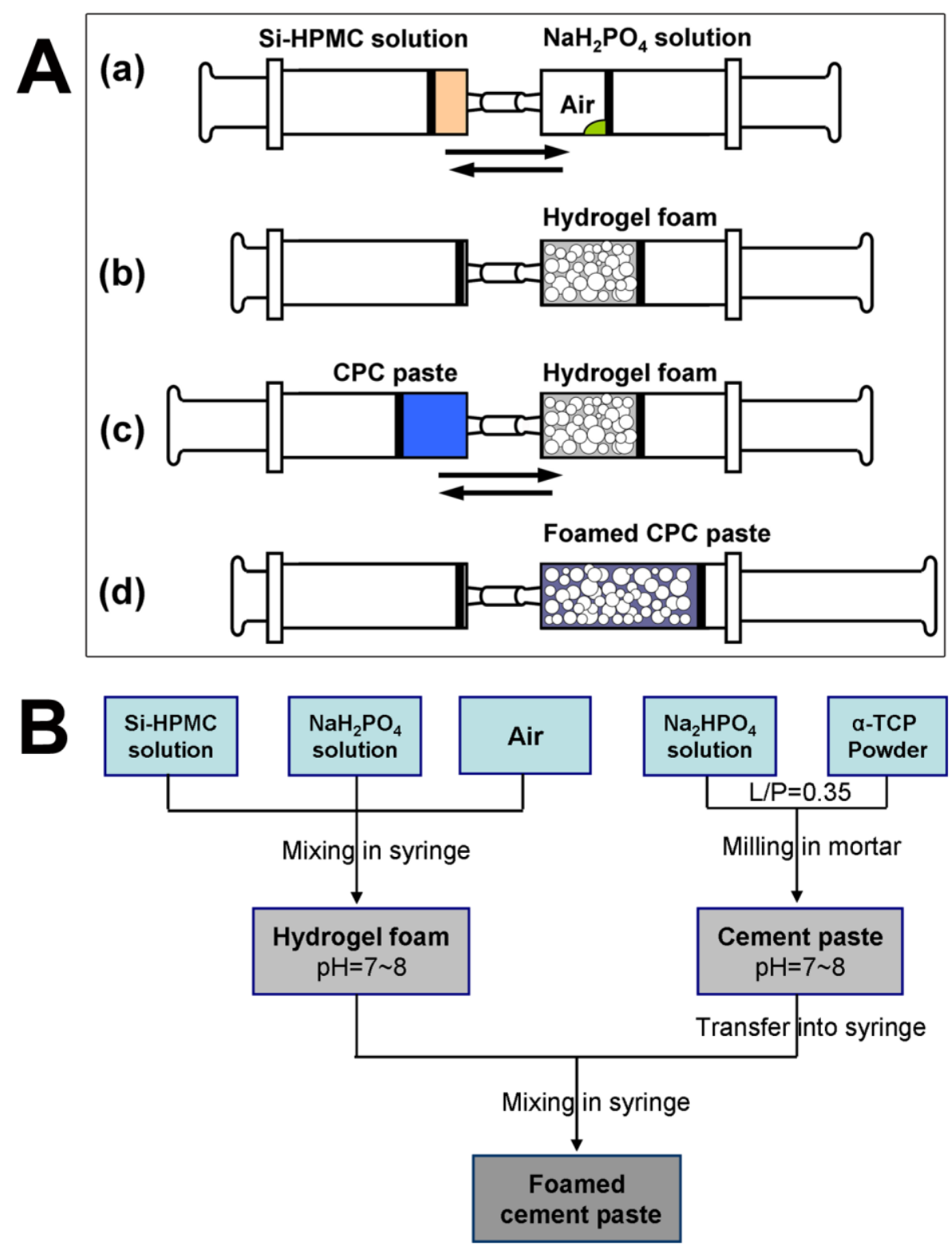

Fig.1 (A) schema and (B) flow chart showing the preparing process of the Si-HPMC hydrogel foam and the foamed CPC paste.

\subsection{Evaluation of injectability and cohesion}

The injectability of the Si-HPMC foamed CPC pastes was tested using a $5 \mathrm{~mL}$ syringe, as described in a previous study [37]. The foamed CPC paste was prepared and immediately extruded from the syringe by a multifunction testing machine (TAHD plus, Stable Micro Systems, UK) at a speed of $15 \mathrm{~mm} / \mathrm{min}$ until a maximum force of $200 \mathrm{~N}$ was reached. The force during extrusion was recorded, and the mass of the paste extruded from the syringe was weighted and divided by the original mass of the paste inside the syringe to calculate the percentage of extruded mass. The tests were performed at $25{ }^{\circ} \mathrm{C}$ with $\sim 50 \%$ 
relative humidity which was measured by hygrothermograph. Each measurement was carried out in triplicate. To assess the cohesion, the newly prepared foamed CPC paste was immediately injected into a saline solution at $37^{\circ} \mathrm{C}$, and the foamed $\mathrm{CPC}$ paste was observed during hardening.

\subsection{Measurement of mechanical properties}

The cuboid foamed CPC specimens $\left(36 \times 8 \times 8 \mathrm{~mm}^{3}\right)$ were prepared and used to test the Young's modulus and flexural strength in wet conditions, i.e. tested immediately after taking the specimens out of the saline solution after 5 days hardening. A standard three-point bending test with a span of $32 \mathrm{~mm}$ was used to load the CPC specimens at a crosshead speed of $0.1 \mathrm{~mm} / \mathrm{min}$ on a computer-controlled universal testing machine (MTS, USA). Specimen deflection was measured using a Linear Variable Differential Transformer (LVDT), with a precision of less than a micrometer. Each test was performed in triplicate.

The cylindrical foamed CPC specimens (6 $\mathrm{mm}$ diameter, $12 \mathrm{~mm}$ height) were prepared and used to measure the compressive strength at a loading speed of $0.5 \mathrm{~mm} / \mathrm{min}$ on the same machine. A single sheet of thin cardboard was inserted between the loading plates and the specimens to compensate for any surface irregularities of specimens in contact with the loading plates and lead to a uniform load distribution. Six specimens were measured for each value of compressive strength.

\subsection{Measurement of porosity and pore size distribution}

To determine the porosity, the cylindrical foamed CPC specimens were prepared and dried in a homothermal oven at $37{ }^{\circ} \mathrm{C}$ for several days until there was no more weight loss. The total porosity of Si-HPMC foamed CPC, $\mathrm{P}_{\text {total }}$, was calculated by using the following equation:

$$
P_{\text {total }}=1-\rho / \rho \text { CDHA }
$$

where $\rho_{\mathrm{CDHA}}$ is the density of fully dense CDHA and $\rho$ is the apparent density of foamed CPC specimens determined by dividing their weight by their volume. The average $\rho_{\mathrm{CDHA}}$ of foamed $\mathrm{CPC}$ specimens is $2.74 \mathrm{~g} / \mathrm{cm}^{3}$, which was measured by Accupyc II 1340 density analyzer. Six specimens were used for each measurement of porosity.

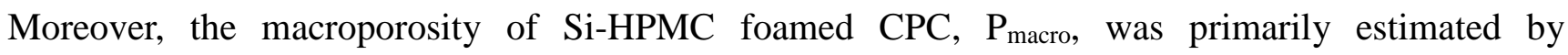
subtracting the total porosity of corresponding CPC fabricated without air, namely $\mathrm{P}_{\text {micro, }}$, from the total porosity of Si-HPMC foamed CPC, $\mathrm{P}_{\text {total }}$ as defined above, using the following equation:

$$
\mathrm{P}_{\text {macro }}=\left(\mathrm{P}_{\text {total }}-\mathrm{P}_{\text {micro }}\right) /\left(1-\mathrm{P}_{\text {micro }}\right)
$$

which is equivalent to a previously reported method [35] used to estimate macroporosity from the measurement of total porosity of macroporous specimens and of the microporosity of cements without 
macropores but prepared with the same L/P ratio.

In addition, micro-computed tomography (micro-CT) scanning (microscanner Skyscan 1072 operating at $70 \mathrm{kV}$ ) was used to assess the sizes and distribution of pores, especially macropores in Si-HPMC foamed CPCs. The minimal resolution of the CT scanning is $7.5 \mu \mathrm{m}$, thus only pores larger than $7.5 \mu \mathrm{m}$ can be measured by this analysis method. The pore size distribution was calculated using software of CT Analyser with 2D and 3D analysis.

\subsection{Phase and microstructure characterization}

After measurement of mechanical properties, the fracture surfaces of foamed CPC specimens were observed using a scanning electron microscope (SEM; Merlin, Carl Zeiss, Germany) equipped with an energy dispersive X-ray (EDX) microanalyzer. Afterwards, the foamed CPC specimens were crushed into powder and their compositions were examined by $\mathrm{XRD}$ using $\mathrm{Cu} \mathrm{K \alpha}$ radiation $(40 \mathrm{kV}, 40 \mathrm{~mA})$ in a continuous scanning mode. The diffraction angle $2 \theta$ varied from $10^{\circ}$ to $80^{\circ}$ at a step size of $0.0167^{\circ}$ with a collection time of $20 \mathrm{~s}$ per step. The infrared absorption spectra of the CPC specimens were characterized by Fourier transform infrared spectroscopy (FTIR; Magna-IR 550, Nicolet Co., USA) in the range of $4000 \sim 400 \mathrm{~cm}^{-1}$.

\subsection{In vivo study}

\subsubsection{Surgical procedures}

For the in vivo study, all the materials and tools used to prepare the Si-HPMC foamed CPC paste were sterilized. The solid powder was sterilized by heating at $200{ }^{\circ} \mathrm{C}$ for 12 hours, the others were sterilized by steam at $121^{\circ} \mathrm{C}$ for $20 \mathrm{~min}$. The Si-HPMC foamed CPCs were prepared extemporaneously in the surgical room next to the animals under aseptic condition and implanted bilaterally in 2 New Zealand white rabbits under general anaesthesia, following the method reported in previous studies [37-40]. Lateral arthrotomy was performed at the knee joint and a cylindrical (6 mm diameter, $10 \mathrm{~mm}$ height $)$ defect was created at the distal end of rabbit femur. A freshly prepared Si-HPMC foamed CPC paste was injected to fill the defect after saline irrigation and carefully drying of the osseous cavity. Then the subcutaneous tissues and skin were closed in layers. All the animal handling and surgical procedures were conducted according to European community guidelines for the care and use of laboratory animals (DE 86/609/CEE) and approved by the ethical committee of local veterinary school.

The rabbits were killed respectively after one-week and six-week implantation by an intracardiac injection of a barbituric substance. Femoral extremities were excised, and fixed in neutral buffered 
formalin solution for 48 hours, and then dehydrated in graded ethanol and acetone. Finally, the non-decalcified bone specimens were embedded in polymethyl methacrylate resin.

\subsubsection{Histological evaluation}

Each block of the non-decalcified bone specimens was cut in half with a circular diamond saw (saw microtome 1600, Leica, Germany). One part was polished on the bone-implant surface and sputtered with gold/palladium alloy for SEM observation using backscattered electrons (BSE) at $20 \mathrm{kV}$ (LEO 1450VP, Zeiss, Germany). The whole surface of the bone-implant was divided into 30 contiguous fields and recorded on SEM at a magnification of 50. With image analysis, the threshold was determined by the operator for the areas of CPC, soft tissues and newly formed bone in each field and then the areas of newly formed bone were identified with artificial colors. The other part was performed on $10-\mu \mathrm{m}$-thick serial sections by using a hard tissue microtome (Reichert-Jung, Supercut 2050, Germany) and stained with Movat's pentachrome for light microscopy observations on a Nikon Eclipse TE2000-E microscope (Solent Scientific limited, France).

\section{Results}

\subsection{Injectability and cohesion}

The injectability of the Si-HPMC foamed CPC pastes at different total L/P ratios and with various volumes of air entrained were assessed by the mass percentage of extruded paste and all the pastes studied were extruded completely from the syringe, which indicated an outstanding injectability. Since all the CPC pastes were completely extruded, the graph of percentage of extruded mass is not shown here. The extrusion curves during injection of the foamed CPC pastes were recorded to further illustrate the extrusion process, as shown in Fig.2A. The overshoot at the beginning of the curve means the yield stress which is the critical force that must be applied to make the paste start to flow. Subsequently, the plateau, which is related to the load needed to maintain the paste flow, can be observed for all the CPCs with or without foamed, indicating a homogeneous extrusion. Moreover, the plateau for the foamed CPCs is longer than that of the corresponding non-foamed CPCs, and it is due to the large volume of entrained air bubbles which enlarges the total volume of the cement paste. Finally, the extrusion force at the plateau increases with the decreasing $\mathrm{L} / \mathrm{P}$ ratio, which is simply due to the correspondingly increasing viscosity of the cement paste. At the end of the extrusion, the force increases steeply until reaching the maximal extrusion force, which is caused by the mechanical contacts between syringe plunger and its bottom when 
all the paste is extruded.

As shown in Fig. 2B and C, even entraining a large amount of air bubbles, the Si-HPMC foamed CPCs still demonstrated an excellent cohesion. Indeed, when injected into the saline solution immediately after preparation (<3 minutes), the Si-HPMC foamed CPC paste maintained its noodle-like shape until hardening, during which no disintegration was observed (Fig. 2B). Moreover, because of the numerous air bubbles entrained, the density of the foamed Si-HPMC composite cement was very low, thus the cement floated in the saline solution (Fig. 2C) even after complete hardening.
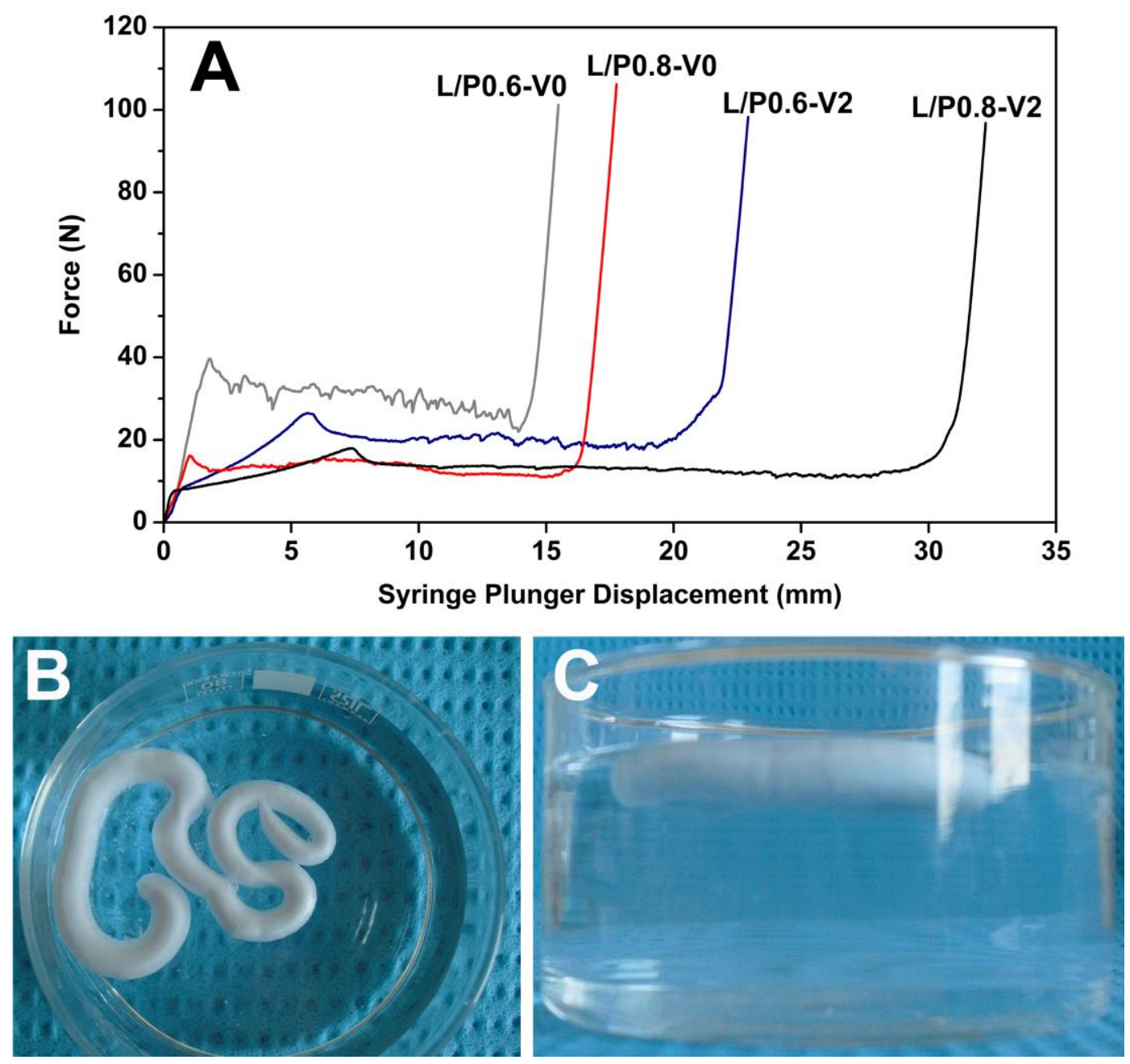

Fig.2 (A) Injection force curves during extrusion of the Si-HPMC foamed CPC pastes at different total $\mathrm{L} / \mathrm{P}$ ratios and volumes of air entrained. ( $\mathrm{V} 0$ and $\mathrm{V} 2$ is short for $\mathrm{V}_{\text {air }} / \mathrm{V}_{\text {hydrogel }}=0$ and 2.); Photos of $\mathrm{Si}$-HPMC foamed CPCs injected into a saline solution immediately after preparation (within $3 \mathrm{~min}$ ): (B) overhead view, no disintegration was observed; (C) side view, showing the paste floating in the saline solution, indicating a low density ( or high porosity) $\left(\mathrm{L} / \mathrm{P}_{\text {total }}=0.8, \mathrm{~V}_{\text {air }} / \mathrm{V}_{\text {hydrogel }}=2\right)$.

\subsection{Pore size and microstructure}

The total porosities and macroporosities of Si-HPMC foamed CPCs were plotted as function of 
$\mathrm{V}_{\text {air }} / \mathrm{V}_{\text {hydrogel }}$ ratio (Fig. 3). The total porosity of the Si-HPMC foamed CPCs increased not only with the increasing total $\mathrm{L} / \mathrm{P}$ ratio but also with the increasing volume of air introduced. Similarly, the macroporosity increased with the increasing of the volume of air introduced, and the macroporosity of the Si-HPMC foamed CPCs with a total L/P ratio of 0.8 was also higher than that of the corresponding foamed CPCs with a lower L/P ratio due to its larger volume of Si-HPMC hydrogel used for foaming.

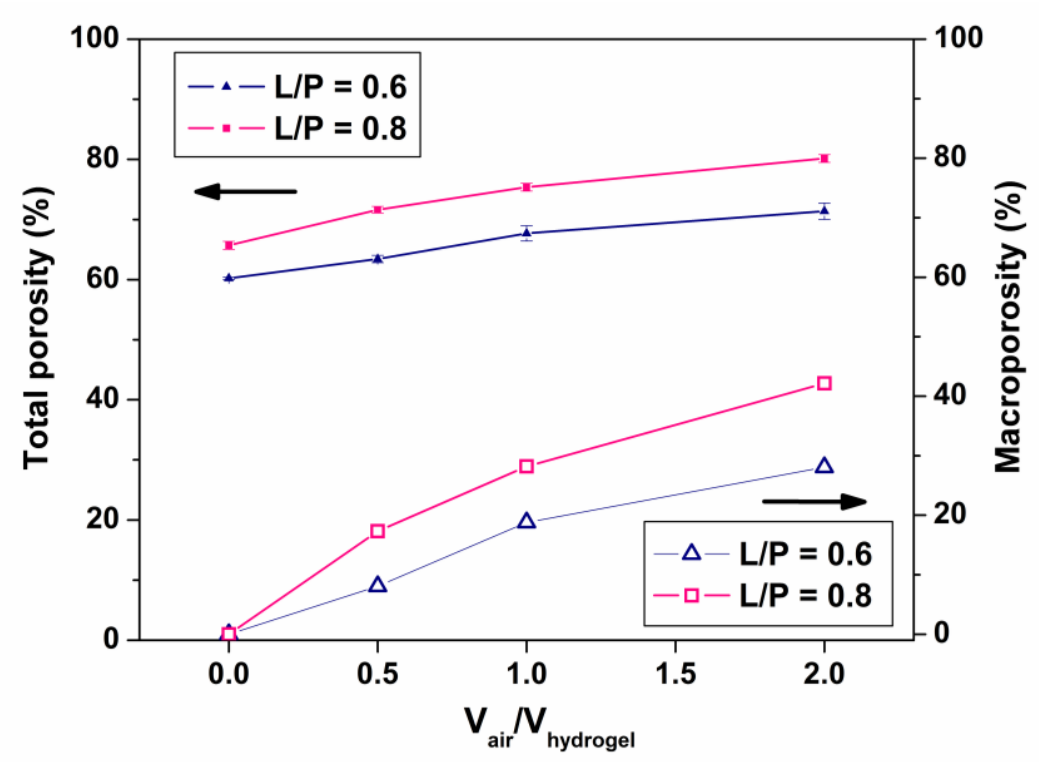

Fig.3 Total porosity and estimated macroporosity of Si-HPMC foamed CPCs as function of $\mathrm{V}_{\text {air }} / \mathrm{V}_{\text {hydrogel }}$ ratio. Each value is the mean of six measurements \pm one standard deviation.

By using the micro-CT scanning, only a few macropores was observed in the cross section of the foamed CPCs with a total $\mathrm{L} / \mathrm{P}$ ratio of 0.6 and a $\mathrm{V}_{\text {air }} / \mathrm{V}_{\text {hydrogel }}$ ratio of 0.5 (Fig. 4A). Both the number and size of the macropores increased with increasing $\mathrm{V}_{\text {air }} / \mathrm{V}_{\text {hydrogel }}$ ratio (Fig. $4 \mathrm{~B}, \mathrm{C}$ ). In contrast, plenty of macropores appeared in the cross section of the foamed CPCs with a higher total L/P ratio of 0.8 and a $\mathrm{V}_{\text {air }} / \mathrm{V}_{\text {hydrogel }}$ ratio of 0.5 (Fig. 4D). In addition, the number and size of the macropores increased significantly with the increasing $\mathrm{V}_{\text {air }} / \mathrm{V}_{\text {hydrogel }}$ ratio (Fig. 4E and $\mathrm{F}$ ). 

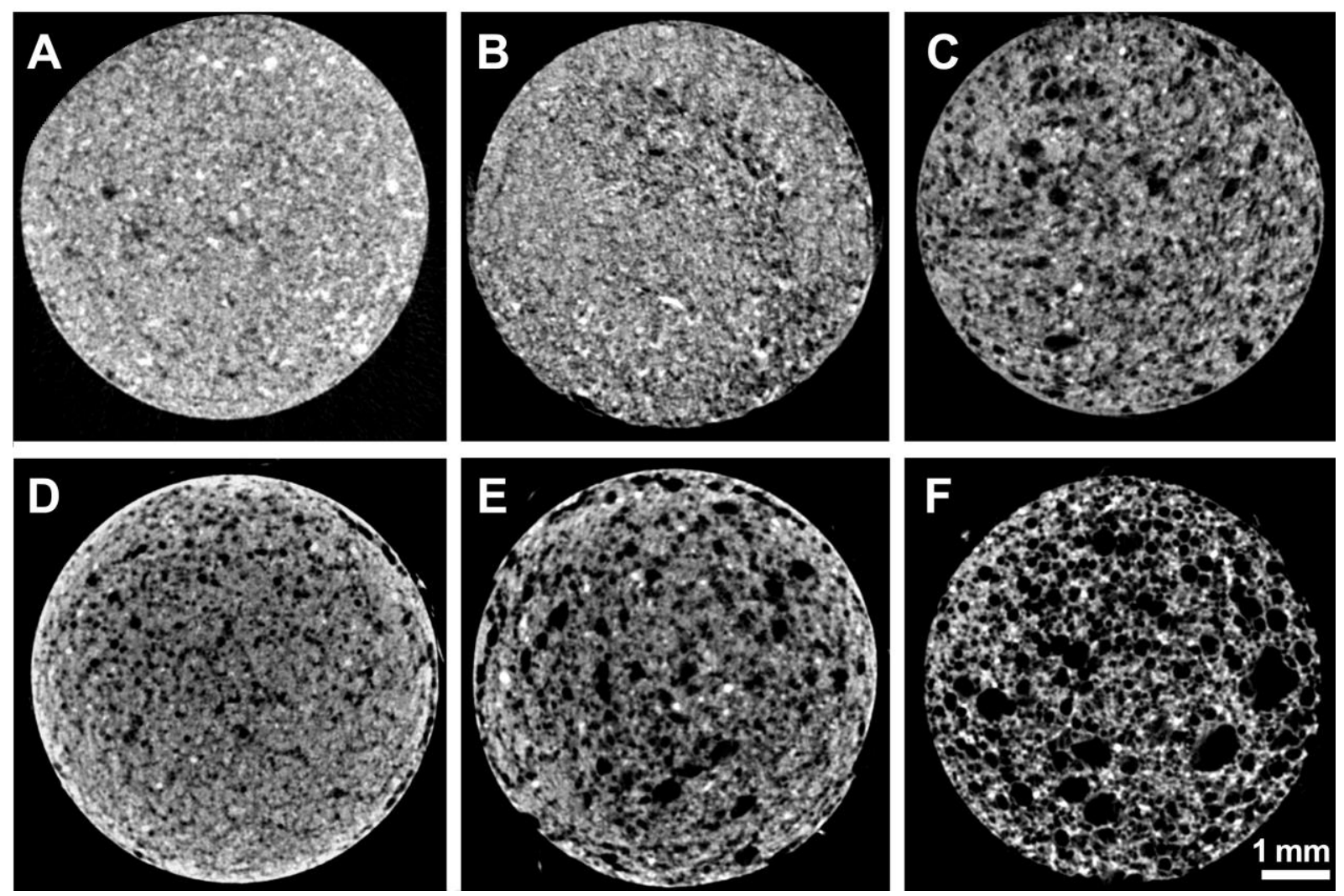

Fig.4 Micro-CT scanning of the cross sections of the Si-HPMC foamed CPCs with different total L/P ratios $(\mathrm{A}, \mathrm{B}$ and $\mathrm{C}: \mathrm{L} / \mathrm{P}$ total $=0.6 ; \mathrm{D}, \mathrm{E}$ and $\mathrm{F}: \mathrm{L} / \mathrm{P}$ total $=0.8)$ and different volumes of air entrained $(\mathrm{A}$ and D: V0.5; B and E: V1.0; C and F: V2.0). V0.5, V1.0 and V2.0 are short for $\mathrm{V}_{\text {air }} / \mathrm{V}_{\text {hydrogel }}=0.5,1.0$ and 2.0, respectively.

The pore size distribution of the Si-HPMC foamed CPCs with different total L/P ratios and volumes of air entrained were calculated basing on the three-dimensional volume formed by combining all the scanned cross sections together (Fig. 5). Both Si-HPMC foamed CPCs with a total L/P ratio of 0.6 and 0.8 showed a hierarchical pore size distribution. For the foamed CPCs with a total L/P ratio of 0.6, the pore size distributions presented a peak centered on around $50 \mu \mathrm{m}$ (Fig. 5A), and this size tended to increase slightly with the increasing $\mathrm{V}_{\text {air }} / \mathrm{V}_{\text {hydrogel }}$ ratio (Fig. 5B and C). The foamed CPCs with a total L/P ratio of 0.8 showed similar findings: the peak center of pore size distribution increased from around $50 \mu \mathrm{m}$ to around $100 \mu \mathrm{m}$ with increasing $\mathrm{V}_{\text {air }} / \mathrm{V}_{\text {hydrogel }}$ ratio from 0.5 to 2.0 (Fig.5D, E and F). However, the macropores with sizes over $300 \mu \mathrm{m}$ were noticeable only in the foamed CPC with a total L/P ratio of 0.8 and a $\mathrm{V}_{\text {air }} / \mathrm{V}_{\text {hydrogel }}$ ratio of 2.0 (Fig.5F). 

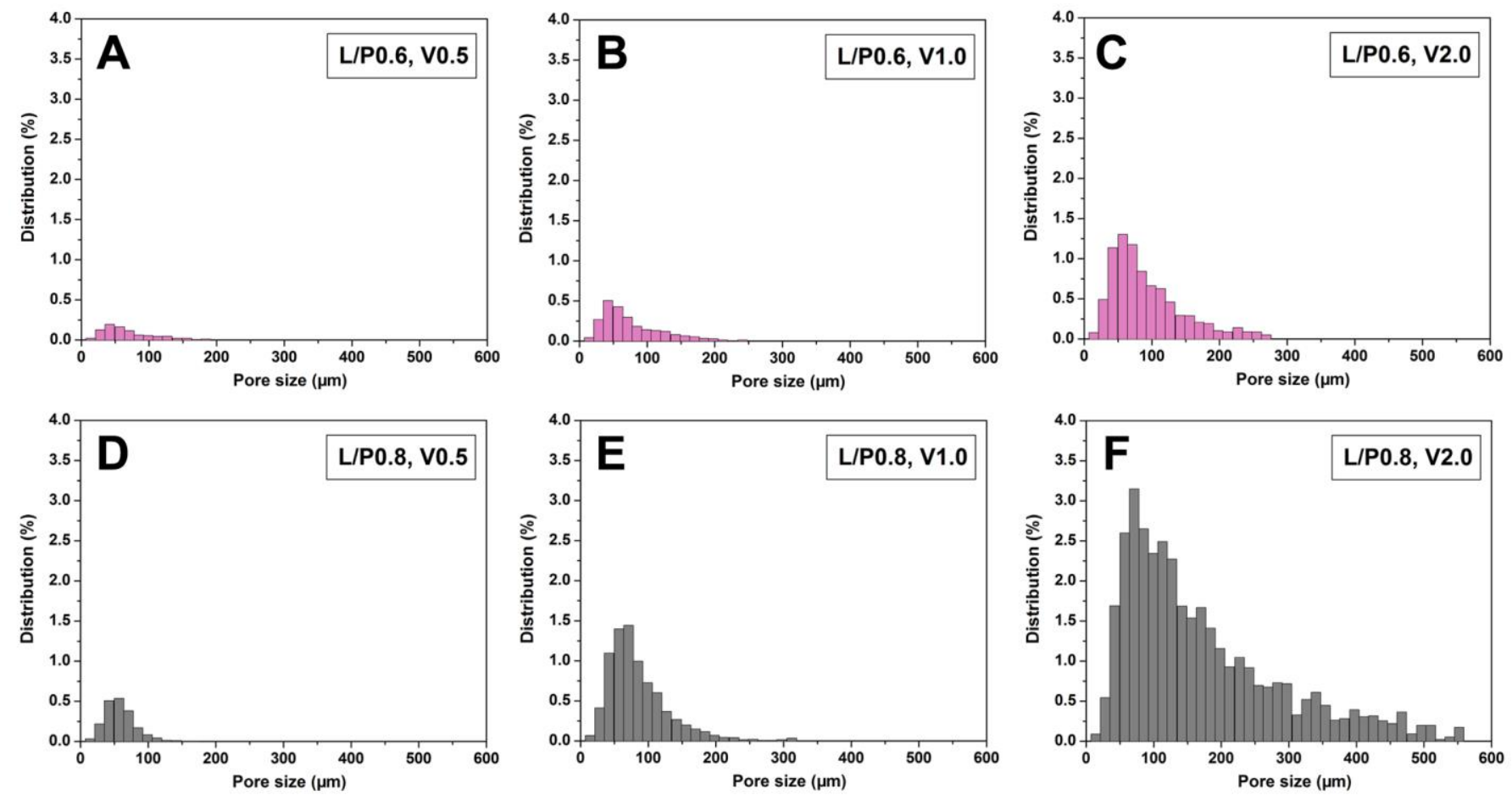

Fig.5 Pore size distribution of the Si-HPMC foamed CPCs with different total L/P ratios (A, B and C: L/P total $=0.6 ; \mathrm{D}, \mathrm{E}$ and $\mathrm{F}: \mathrm{L} / \mathrm{P}$ total $=0.8)$ and different volumes of air entrained (A and D: V0.5; B and E: V1.0; $\mathrm{C}$ and F: V2.0). V0.5, V1.0 and V2.0 are short for $\mathrm{V}_{\text {air }} / \mathrm{V}_{\text {hydrogel }}=0.5,1.0$ and 2.0, respectively. The pore size distribution on the 3-Dimensional scale is based on the total volume of the specimen.

The microstructure of the Si-HPMC foamed CPCs was also observed by SEM. The micrographs showed that numerous spherical macropores of various sizes seemed to be arbitrarily distributed in the foamed CPCs with a total $\mathrm{L} / \mathrm{P}$ ratio of 0.8 and a $\mathrm{V}_{\text {air }} / \mathrm{V}_{\text {hydrogel }}$ ratio of 1.0 (Fig. 6A). With increasing $\mathrm{V}_{\text {air }} / \mathrm{V}_{\text {hydrogel }}$ ratio up to 2.0, numerous macropores were observed with distorted shapes and larger sizes (Fig. 6B). Under a higher magnification, the glue-like polymer, which is probably derived from shrunk Si-HPMC hydrogel after drying, was visible in the cement matrix between macropores (Fig. 6C), sticking to adjacent apatite crystals. It was also found that, whether in the cement matrix between macropores or on the wall of macropores, the micro-morphology of apatite crystals were sheet-like shape, which was similar to that of apatite crystals in the CPCs matrix without any additives (Fig. S1) [34]. Moreover, the final phases of CPCs with or without Si-HPMC after hardening for 5 days were examined by XRD, as previous study [34], and no evident difference was observed between the two XRD patterns. In addition, polymer films on the wall the macropores were observed in the Si-HPMC foamed CPCs (Fig. 6D). 

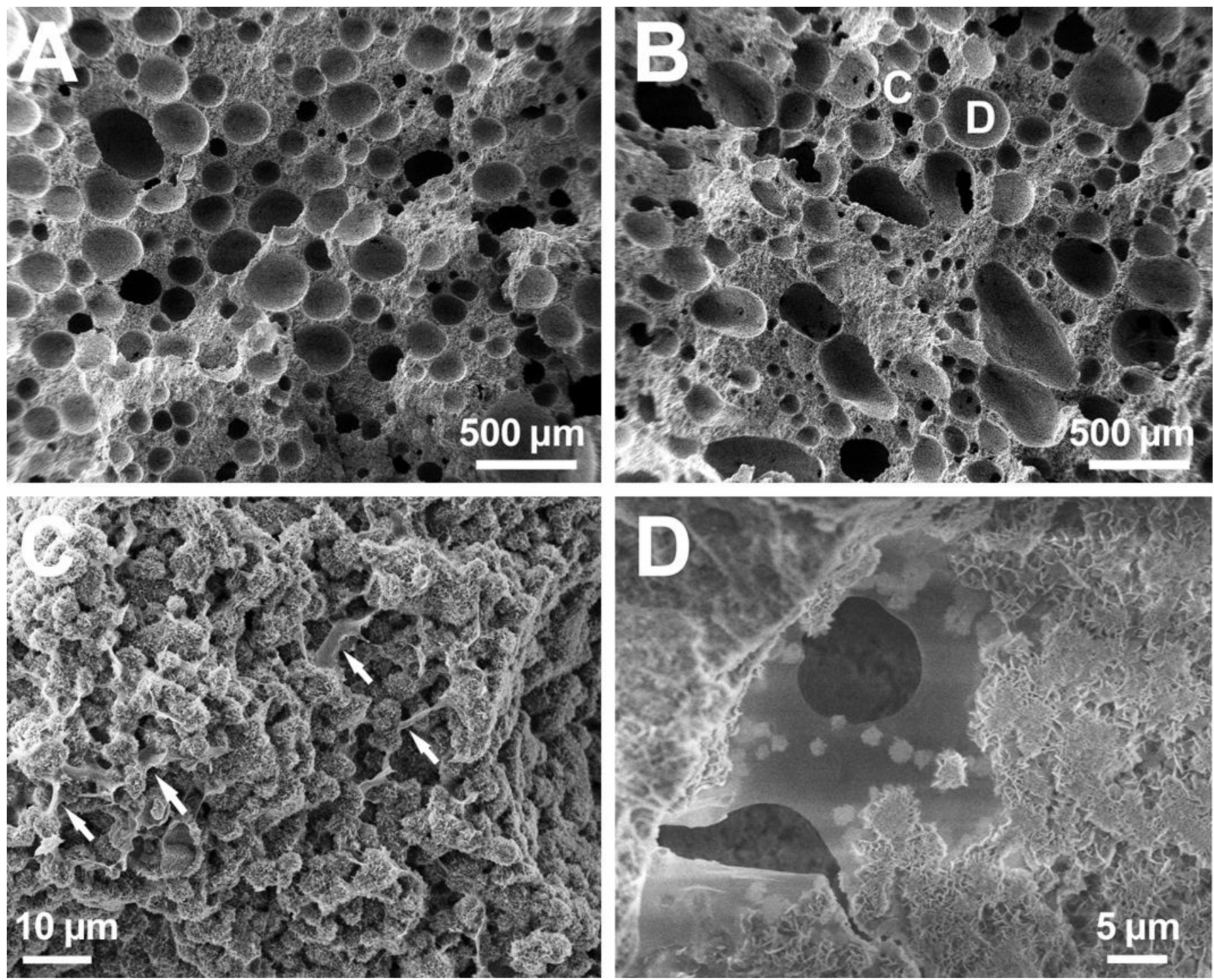

Fig.6 SEM images of the fracture surfaces of Si-HPMC foamed CPCs) with different volumes of air entrained. (A) $\mathrm{L} / \mathrm{P}_{\text {total }}=0.8, \quad \mathrm{~V}_{\text {air }} / \mathrm{V}_{\text {hydrogel }}=1.0 ;$ (B) $\mathrm{L} / \mathrm{P}_{\text {total }}=0.8, \mathrm{~V}_{\text {air }} / \mathrm{V}_{\text {hydrogel }}=2.0 ;$ (C) the micro-morphology of cement matrix between macropores, the arrows in the image point to shrunk Si-HPMC polymers sticking to apatite crystals; (D) the micro-morphology on the wall of a macropore.

\subsection{Mechanical properties}

The mechanical properties of the Si-HPMC foamed CPCs were plotted as functions of macroporosity

(Fig.7). As expected, all the mechanical properties measured decreased with the increasing macroporosity

(Fig.7A, B and C). Moreover, the compressive strength presented a sharp decrease as soon as the macropores are introduced (Fig.7C). Finally, the stress-displacement curves were recorded during compression tests of the Si-HPMC foamed CPCs with different volume of air entrained, as shown in Fig.7D. A sharp drop of the loading stress was observed in the control cement without Si-HPMC additives, which is related to a brittle fracture. On the contrary, for the CPCs with Si-HPMC but without foaming $\left(\mathrm{V}_{\text {air }} / \mathrm{V}_{\text {hydrogel }}=0\right)$, a mild drop of the loading stress was found, indicating a kind of tolerance to damage. Furthermore, the mild drop of the loading stress became more obvious in the foamed CPCs with different 
amounts of air introduced (from V0.5 to V2.0).
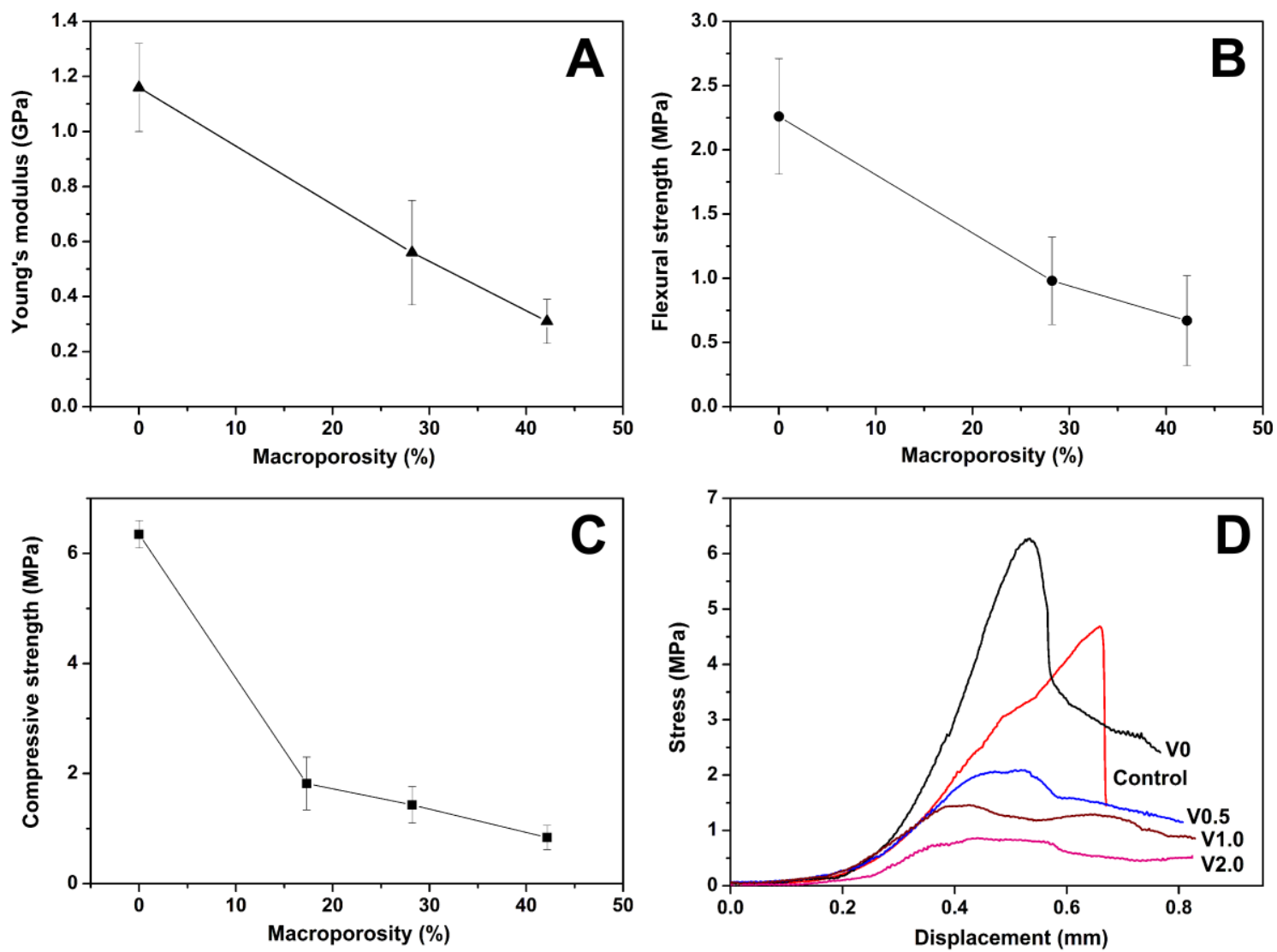

Fig.7 The mechanical properties (A) Young's modulus, (B) Flexural strength and (C) Compressive strengths of foamed Si-HPMC composite cement as function of macroporosity. (D) Stress versus displacement curves of the control cement (CPC without Si-HPMC additives) and the Si-HPMC foamed CPCs with different amounts of air introduced. V0, V0.5, V1.0 and V2.0 are short for $\mathrm{V}_{\text {air }} / \mathrm{V}_{\text {hydrogel }}=0$, $0.5,1.0$ and 2.0 respectively $\left(\mathrm{L} / \mathrm{P}_{\text {total }}=0.8\right)$.

\subsection{Preliminary in vivo study}

No evidence of adverse foreign body reaction was observed in 1-week and 6-week implantation sites in femoral defects of rabbits. In the SEM image of 1-week implantation site (Fig. S2 A), it can be found that the Si-HPMC foamed CPCs entirely filled in the original bone defect and maintained the macroporous structure during the implantation period. After 6 weeks, the SEM images (Fig. 8A, C) showed that the newly formed bone was presented in the deep zone of implantation site, closely contacting with the inside walls of macropores. It was also found that some of the walls between macropores disappeared and the macropores became interconnected with each other, and in some cases the spaces previously occupied by CPC were filled by newly formed bone, which support the bone tissue structure subsequently (Fig. 8C). Furthermore, in the histological photos of the same sample, not only newly mineralized bone but also osteoid tissue, cells and macrophages appeared in the deep zone of implantation site (Fig. 8B and D). In 
addition, after 1-week implantation, a discontinuous black gap could be observed between Si-HPMC foamed CPCs and host bone (Fig. S2 A). The histology images observed by using light microscopy indicated that the black gap was not empty; instead, it was unmineralized soft tissue (Fig. S2 D). Meanwhile, a few osteoid tissue was observed closely in connect with host bone at the periphery of implantation site. Similarly, after 6-week implantation, there were also some black gaps observed between CPC and host bone (Fig. 8E). Through light microscopy, it was observed that the black gap was unmineralized soft tissue together with numerous macrophages and some osteoid tissue (Fig. 8F). The histological morphology of the same sample was further revealed at a higher magnification (Fig. 9). The osteoid tissue, macrophages and normal cells were clearly seen both at the periphery (Fig. 9A) and in the center (Fig. 9B) of implantation site. 

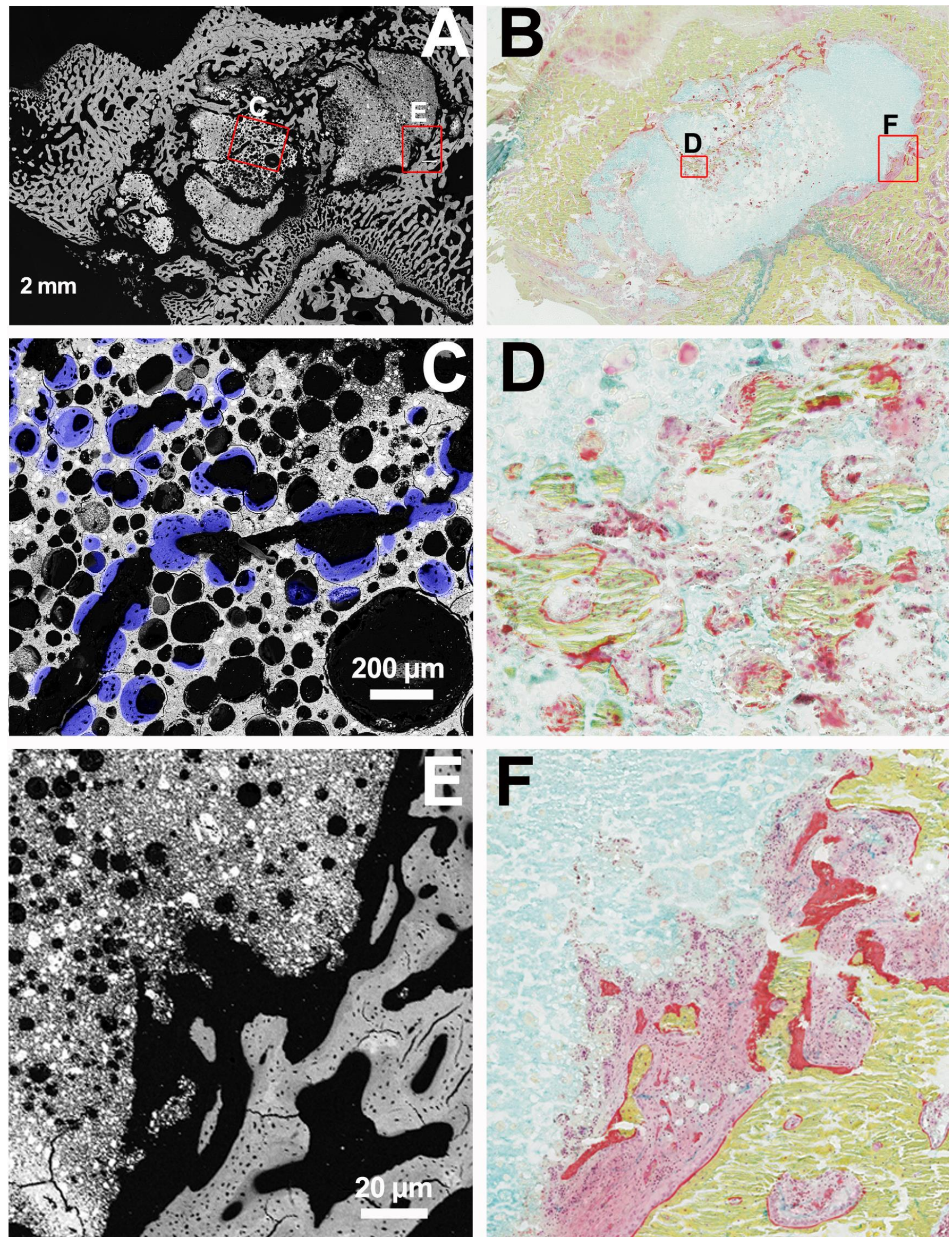

Fig.8 (A) the SEM examination using BSE of 6-weeks implantation site in rabbit femur; (B) histology 
photos of the same sample after Movat's staining; (C) zoom area of SEM image in the deep zone of defect (original magnification $\times 10$ ), the areas of newly mineralized bone were colored with dark blue; (D) zoom area of histology photo in the deep zone of defect (original magnification $\times 20$ ), the newly mineralized bone (green), osteoid tissue (red), macrophages (with nuclei as extremely dark dots) and normal cells (pink) are visible in the matrix of biocement (light blue); (E) zoom area of SEM image on the interface between the biocement and host bone (original magnification $\times 12.5$ ); (F) zoom area of histology photo on the interface between the biocement and host bone (original magnification $\times 12.5$ ); the osteoid tissue (red) closely connected with host bone (green), macrophages (with nuclei as extremely dark dots) and in some cases the soft tissue (pink) are presented between the biocement (light blue) and host bone.

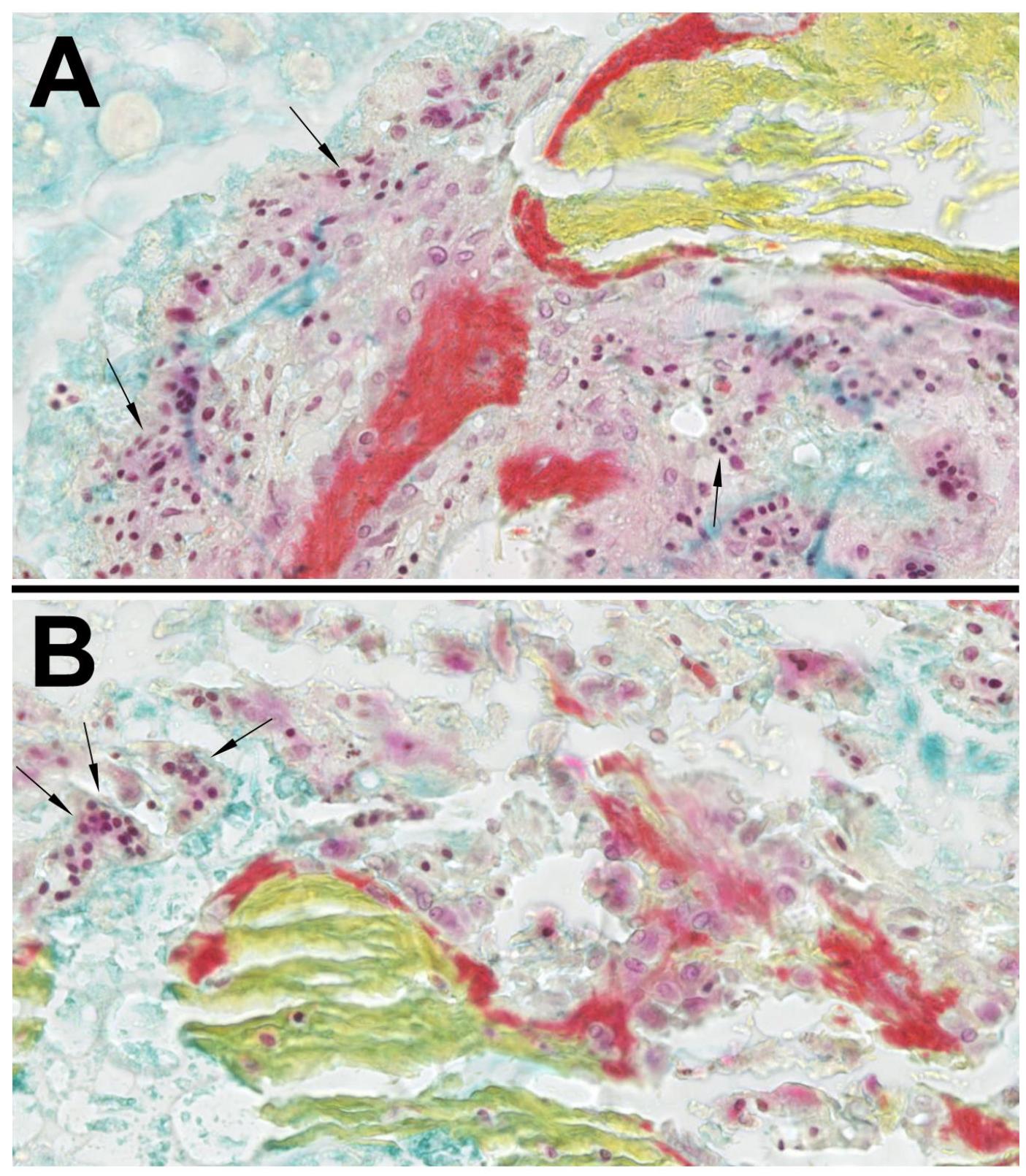

Fig.9 Zoom area of histology photo after Movat's staining (A) at the periphery of the implantation site (original magnification $\times 65$ ) and $(B)$ in the center of implantation site (original magnification $\times 80$ ). The mineralized bone (green), osteoid tissue (red), macrophages (the arrows point to nuclei as extremely 
dark dots) and normal cells (pink) are observed in the matrix of CPC (light blue).

\section{Discussion}

The CPC foaming method by syringes and using cross-linkable hydrogel (Si-HPMC) as a foaming agent to prepare injectable macroporous CPCs in this work is reported for the first time. In the aforementioned approaches proposed by Ginebra's group, the process of foaming liquid phase of CPC is conducted by mechanical stirring with a domestic mixer, and then the cement paste or the powder phase of cement is mixed carefully with foam by spatula to avoid foam disruption [29-31]. For some of the foaming agents, heating is necessary to prepare foam. In the present work, the connected syringes are used to foam the viscous liquid phase and subsequently to mix the CPC paste with the foam, and all the preparation processes can be conducted at room temperature. In this sense, the present method is simpler and easier for clinic applications.

The foaming agent chosen in this work is Si-HPMC, like HPMC, which is a hydrophilic cellulose derivative. Moreover, Si-HPMC can self-crosslink to form a hydrogel. Its rheological properties [41], gelling principle [42] and kinetics of gelation [43] have been thoroughly studied, and its biomedical applications for preparation of biomaterial matrices and injectable calcium phosphate ceramics suspensions have been extensively investigated [40, 44-48], showing a good biocompatibility and bioactivity. The reasons to use Si-HPMC as a foaming agent are as following: firstly, it is a viscous solution before gelation, effectively entrain air bubbles, and avoid their disruption under shearing action or extrusion. Secondly, it can cross-link at room temperature, under easily controllable conditions without use of a toxic chemical catalyst and without intense release of heat, forming a hydrogel with a three dimensional network of Si-HPMC chains to keep the foam in a high stability. It has been tested that the Si-HPMC solution, with a concentration of $4 \mathrm{wt} . \%(\mathrm{w} / \mathrm{v})$, can form a stable foam entraining air whose volume is twice of that of solution, and the foam can keep the structure permanently due to the gelation of Si-HPMC.

The Si-HPMC foamed CPC paste appears a good injectability and excellent cohesion (Fig.2), which is appreciated in clinic application and is believed to be attributed to the increasing viscosity of the CPC paste by Si-HPMC, as reported in previous studies [49-52]. Furthermore, owing to the self-crosslinking of Si-HPMC, the foamed CPC can maintain its shape instead of flowing away from an implant site. This 
feature is important for the clinic applications, especially in the case of open bone defects. Because these properties ensure the performance of the $\mathrm{CPC}$ in vivo, make the $\mathrm{CPC}$ withstand the blood pressure to avoid pore collapsing and have enough resistance to water penetration and disintegration before setting.

It is evident that the Si-HPMC foamed CPCs maintain macropores after injection through syringe and after setting (Fig.6). And another interesting feature to be highlighted in the foamed CPCs is their hierarchical pore structure, where bubbles were introduced during the foaming process of liquid phase and superimposed onto the intrinsic microporosity of the CPC.

It is worth noting that the terms micro and macropores used in this field is different from that proposed by IUPAC (International Union of Pure and Applied Chemistry) which defines micropores as pores smaller than $2 \mathrm{~nm}$ and macropores as pores above $50 \mathrm{~nm}$. It has been clarified that the intrinsic porosity in CPC produced by the spaces created between the precipitated crystals, which is generally smaller than few microns, is identified as microporosity; and the porosity introduced by artificial means, which is larger than $100 \mu \mathrm{m}$, is referred to as macroporosity [53].

A minimum pore size of $100 \mu \mathrm{m}$ has been reported to allow bone ingrowth inside the pores, and the optimum pore size is in the range of 200-400 $\mu \mathrm{m}[53,54]$. In the Si-HPMC foamed CPC with a total L/P ratio of 0.8 and a $\mathrm{V}_{\text {air }} / \mathrm{V}_{\text {hydrogel }}$ ratio of 2.0, there are plenty of macropores with size in the range of $100-400 \mu \mathrm{m}$ (Fig.4F and Fig.5F). Besides pore size, one of the most important factors is the pore interconnectivity. In our case, the macropores are interconnected with each other by intrinsic microporoes which are beneficial for body fluid circulation but not in the optimal interconnection size (for instance around $130 \mu \mathrm{m}$ [54]). However, the higher contact area with body fluids in the macroporous cement can enhance the dissolution and resorption rate, thereby increasing the interconnectivity size; or the degradation of polymer can also achieve this aim (Fig. 6D and Fig. 8C).

As expected, the introduction of macroporosity in the foamed CPCs resulted in a steep decrease in the mechanical properties (Fig.7). This is mainly attributed to the large entrained air bubbles which act as critical flaws. It is important to mentioning that although the mechanical properties of the foamed cements are low, they are still comparable to those reported for cancellous bone $[55,56]$ and they are sufficient to maintain the structure of the tissue layer while vascularisation and tissue ingrowth take place. The further investigation in the curves of non-brittle failure shows the beneficial effect of Si-HPMC on the fracture behavior of the foamed CPCs, which is also consistent with the HPMC/Si-HPMC composite cements in previous study [33, 34]. The study in microstructure (Fig. S1) and final phase [34] of CPC 
with or without Si-HPMC revealed that the Si-HPMC does not evidently change the setting reaction of CPC or the microstructure of final apatite crystal in the foamed CPCs.

In the preliminary in vivo study, the evidence of newly formed bone and osteoid tissue inside the macropores in the deep zone of implantation site (Fig.8C and D) confirms that the present foaming method is effective to promote bone ingrowth in the center of CPC. However, the result of this preliminary in vivo study is not perfect, because the foamed CPCs implant did not directly contact with host bone and there was unmineralized soft tissue between them (Fig.8E and F). In addition, the newly formed bone did not appear throughout the whole implantation site (Fig.8B). In fact, the in vivo evaluation of CPCs has been reported, which showed a good osteoconductivity, easy cells adhesion and proliferation, resulting in a direct contact with CPC implant and host bone $[9,57,58]$. Therefore, the bone cells attachment and proliferation in the Si-HPMC hydrogel are need to be considered.

In previous study, the chondrocytes were successfully cultured and differentiated within Si-HPMC hydrogel scaffold $[44,48]$, and MBMCs (mouse bone mesenchymal cells) entrapped within a composite of Si-HPMC hydrogel and BCP (biphasic calcium phosphate) particles induced bone formation when implanted subcutaneously or intramuscularly [46]. Contrarily, HBMCs (human bone mesenchymal cells) did not proliferate when cultured in vitro in a Si-HPMC hydrogel/BCP composite, even though they were viable and retained their osteoblastic differentiation potential, showing a low amount of cells effectively attached on the BCP particles and lack of HBMCs migration in the hydrogel [59]. It might be because many cell types, among which HBMCs, are required to interact with and to adhere to binding ligands of their micro-environment to proliferate, but the Si-HPMC hydrogel lacks such cell-recognizable ligands $[59,60]$. This hypothesis can also explain the observed proliferation of chondrocytes [44] or human osteosarcoma cell lines [45] within Si-HPMC, considering that these cells do not need extensive interaction with their environment to proliferate.

In addition, the molecular structure of the hydrogel could hinder cellular migration if its mesh size is lower than cell size and if cells cannot degrade it. The Si-HPMC backbone is similar to cellulose with a polysaccharide chain that can be degraded by enzyme, but most of the animals, including humans, do not produce this enzyme. Therefore, this polymer may diffuse into body fluids or may be degraded by phagocytes in vivo. It has been reported that the hydrogel is degraded centripetally by phagocytosis after implantation into rabbit bone defects [40] and there was bone ingrowth towards the center of defects when the Si-HPMC hydrogel/BCP composite was implanted into rabbit bone defects [47], which 
indicated that with the complex in vivo micro-environment and the presence of phagocytes to pave the way, the bone cells can migrate to the BCP particles and colonize the hydrogel.

In view of the above findings, in our case the formation of unmineralized soft tissue between foamed cement and host bone can be explained as following: the Si-HPMC hydrogel introduced macropores in CPC and covered on the surface of apatite crystals. It is likely that the bone cells, on the one hand, may be difficult to adhere on the Si-HPMC hydrogel to proliferate due to lack of the cell-recognizable ligands; on the other hand, they may be difficult to penetrate through this hydrogel, because the mesh size of hydrogel is smaller than cell size, and they may also not able to degrade the hydrogel. Thus the hydrogel film on the surface of cement formed a barrier for the bone cells to proliferate or migrate to CPC. However, the other cells for soft tissue regeneration do not have such limit, as a result the soft tissue occupy the place of the interface between CPC and host bone. In the complex in vivo micro-environment, once phagocytes degrade hydrogel to pave the way, the bone cells can migrate to the CPCs and the bone ingrowth normally takes place at the periphery of implantation site or inside the macropores of CPCs in the deep zone of implantation site. Since the degradation of the hydrogel by phagocytes is not homogeneous, it can explain why the newly formed bone did not appear throughout the whole implantation site. This hypothesis is supported by the evidence that at both of these sites, the newly formed bone, either in the form of mineralized bone or osteoid tissue, appeared simultaneously with macrophages. It seems that there is a competition between macrophages and the other cells for soft tissue: if the macrophages win to degrade the hydrogel earlier than the formation of soft tissue, the bone cells can colonize and form a new bone. The systematically and long-term implantations will be needed to investigate the in vivo behavior of this foamed CPC to improve its specific biofunctionality.

The above results suggested that the present approach is simple, feasible and effective, but the formulation of Si-HPMC hydrogel in this work is perhaps not perfect for the new bone ingrowth. It can be improved by modifying the formulation of the hydrogel or using the other alternative viscous hydrophilic polymeric solution. Indeed, the incorporation of collagen I/III [59], hyaluronic acid, and glycosaminoglycan-like marine polysaccharides (HE800 and GY785) [60] to Si-HPMC hydrogel have been reported significantly induce the bone cells attachment on and in the hydrogel, and make the infiltration and migration of bone cells in the hydrogel became possible.

With regard to the alternative viscous hydrophilic polymer, for instance HPMC is a promising polymer candidate, because its physical or chemical properties are similar to that of Si-HPMC, but its degradation 
rate in vivo is proved suitable for the bone regeneration. It has been reported that the HPMC was incorporated with BCP to prepare the injectable biomaterial and implanted in femoral defects of rabbit, displaying an early and extensive newly formed bone apposition between BCP particles through out the implantation site [38, 61-63]. In fact, HPMC is already well known in the pharmaceutical and food industries and has been widely used for anti-washout agent for CPCs. Its foaming ability and foam stability has been studied. It was found that the HPMC solution of $3 \mathrm{wt} \%$ (w/v) can prepare a stable foam entraining air which volume is twice of that of solution, and maintain the foam structure more than $24 \mathrm{~h}$. The injectable macroporous CPCs using HPMC as foaming agent was successfully prepared, and it as well has good injectability and cohesion (Fig. S4); its porosity and microstructure are similar to that of Si-HPMC foamed one; while its compressive strength is slightly lower than that of the latter (Fig. S5 and Fig. S6). The XRD analysis indicated that the HPMC did not effect the reaction of CPC as well (Fig. S7). It implied that the HPMC foamed CPC is a promising bone substitute which would in favor for the bone regeneration. Besides HPMC, many other viscous hydrophilic polymers are possible to use in the present approach as a foaming agent of CPC for bone substitute.

\section{Conclusion:}

In the present study, a new and simple method to prepare macroprous CPCs is developed by foaming in connected syringes and using Si-HPMC as a foaming agent, taking advantage of its high viscosity and self-crosslinkable properties. The results show that the Si-HPMC foamed CPCs have good injectability, good cohesion, hierarchical macropores and their mechanical properties are comparable with cancellous bone. Moreover, the evidence of new bone growth in the deep zone of implantation site in preliminary in vivo study indicated that this foaming method is feasible and effective. However, the formulation of hydrogel still needs to be improved by incorporating cell binding sites in this hydrogel or looking for the alternative viscous hydrophilic polymers.

\section{Acknowledgements}

We acknowledge financial support from the INSERM and the regional program BIOREGOS II (Pays de la Loire, France). J.Zhang would like to thank the China Scholarship Council for funding. Excellent technical assistance from Fanch Guillou and Yann Borjon-Piron is greatly acknowledged. 


\section{Supporting information}
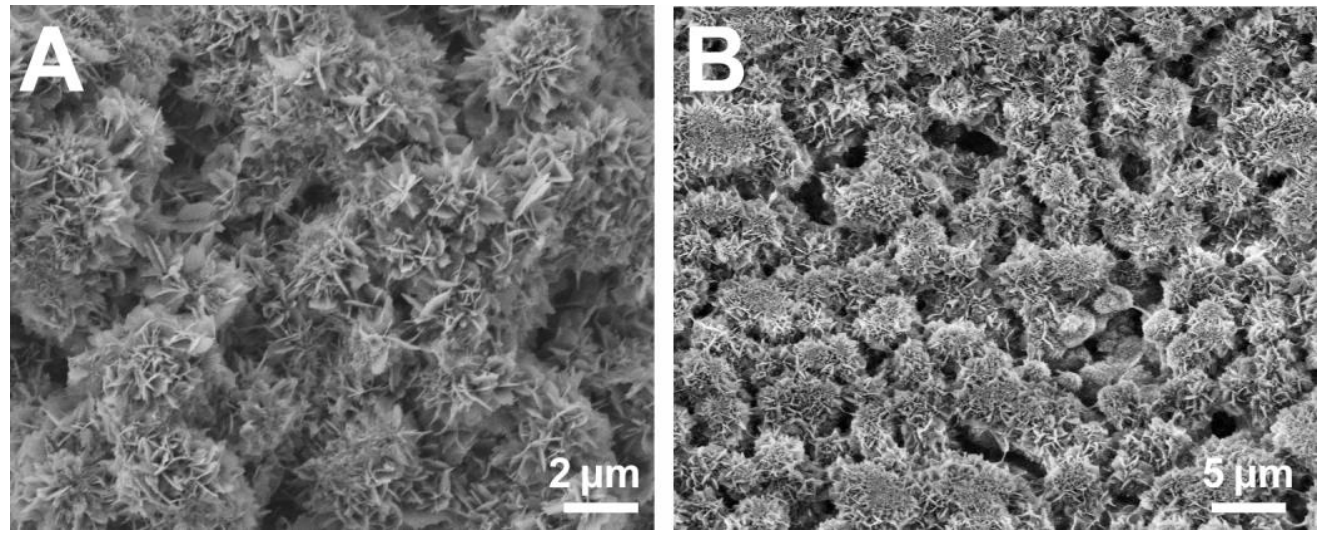

Fig. S1 SEM images of the fracture surfaces of Si-HPMC foamed CPCs in high resolution. (A) cement matrix between macropores; (B) cement matrix on the wall of a macropore. 

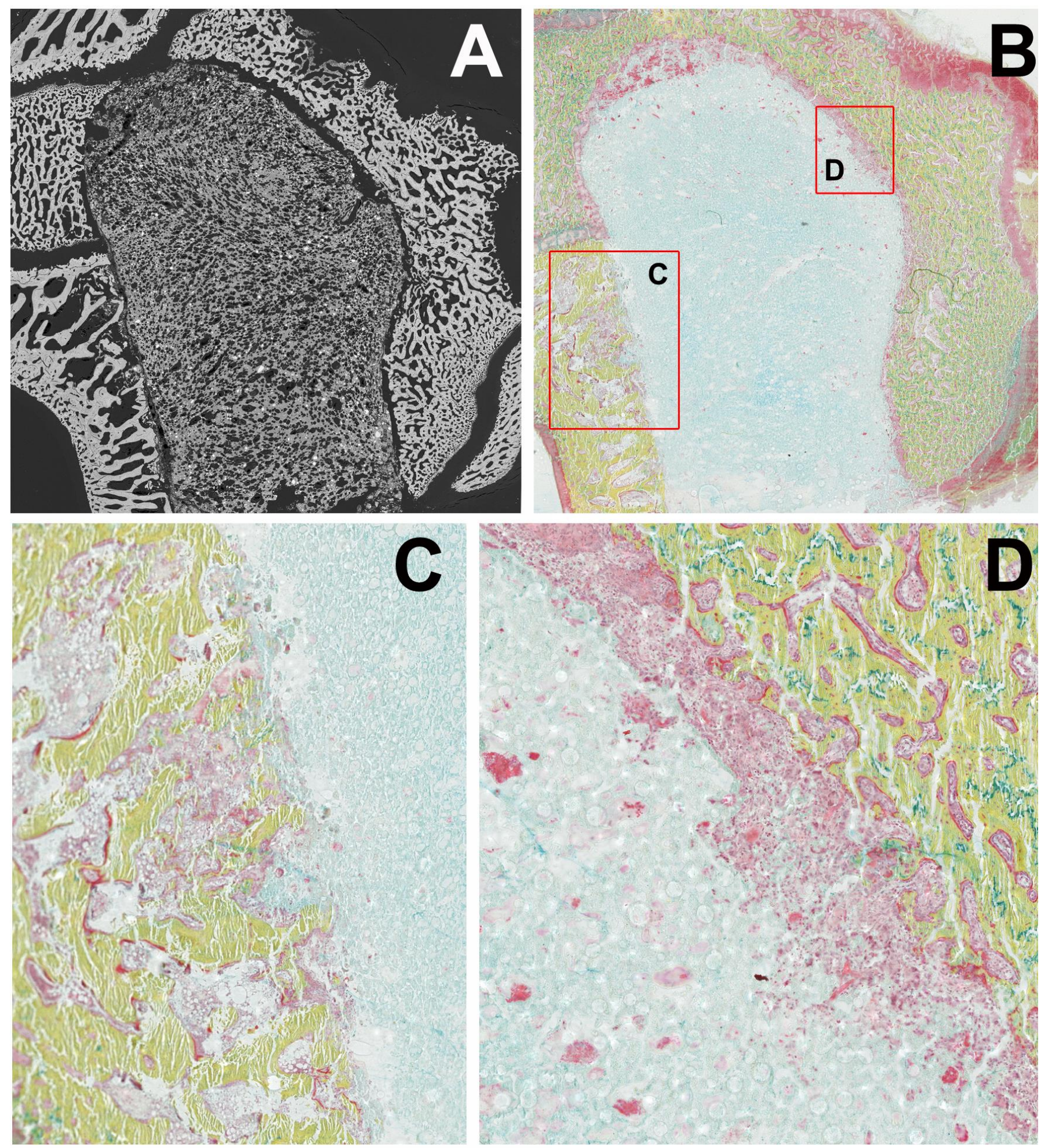

Fig. S2 (A) the SEM examination using BSE of 1-week implantation site in rabbit femur; (B, C and D) histology photos after Movat's staining of the same sample; (C and D) zoom area of image B: the osteoid tissue (red) closely connected with host bone (green). In some cases the biocement directly contacts with the host bone (Figure C), but sometimes, the soft tissue (pink) appears between the biocement (light blue) and host bone (Figure D). 

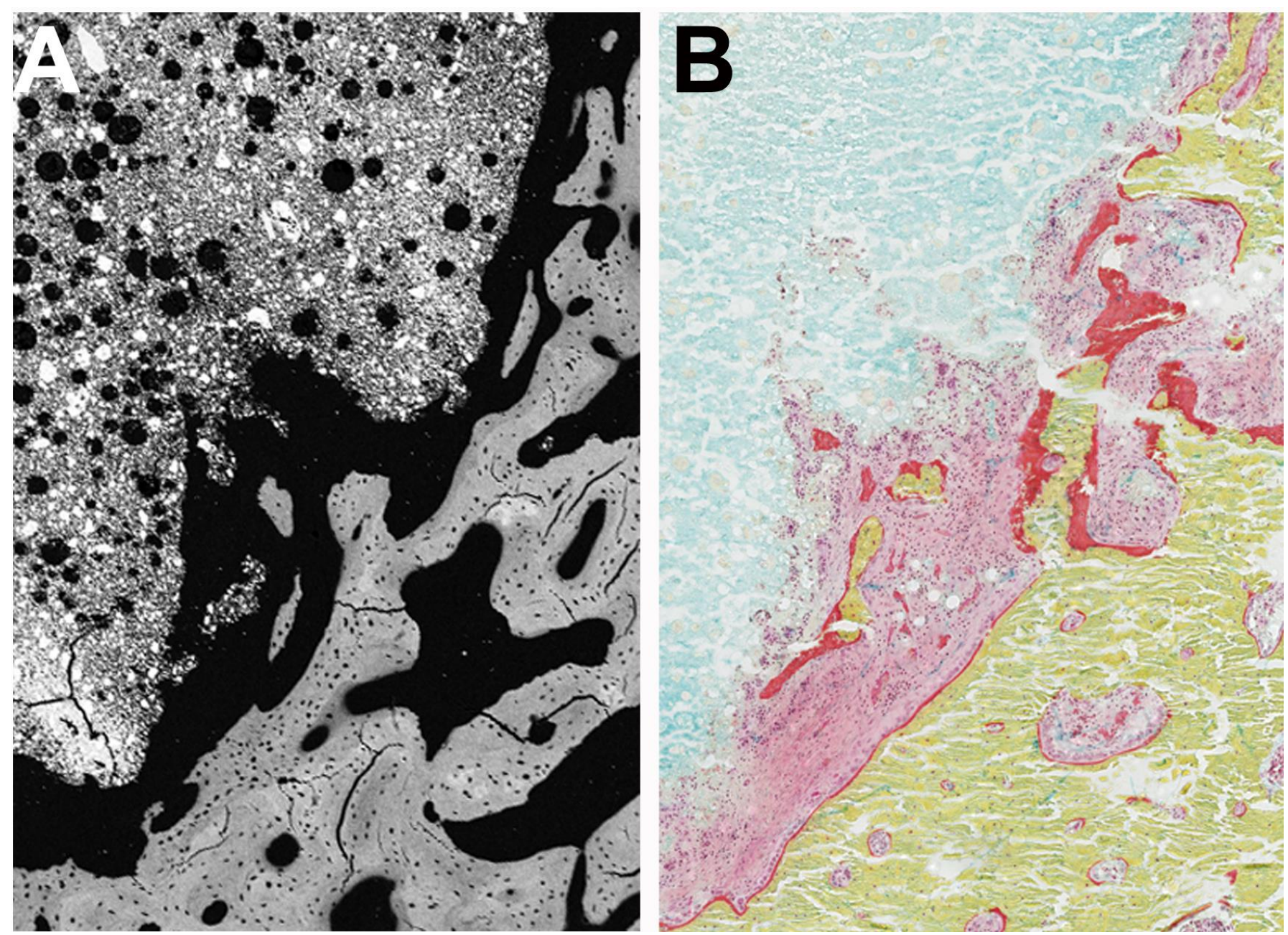

Fig. S3 (A) the SEM examination using BSE and (B) histology photo after Movat's staining on the interface between the biocement and host bone after 6-week implantation. The osteoid tissue (red) is closely connected with host bone (green), and in some case the soft tissue (pink) and macrophages (with nuclei as extremely dark dots) are presented between the biocement (light blue) and host bone.

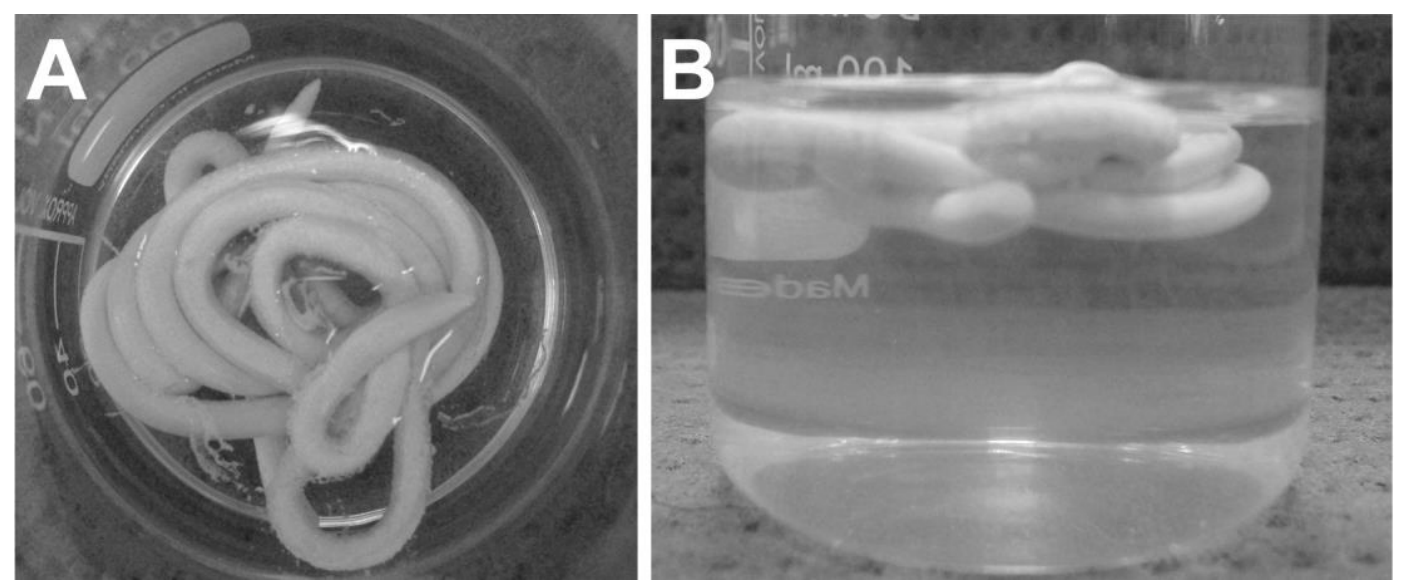

Fig. S4 the photos of HPMC foamed CPCs injected into a saline solution immediately after preparation (within $3 \mathrm{~min}$ ): (A) overhead view, no disintegration was observed; (B) side view, showing the paste floating in the saline solution, indicating a low density or high porosity $\left(\mathrm{L} / \mathrm{P}_{\text {total }}=0.8, \mathrm{~V}_{\text {air }} / \mathrm{V}_{\text {polymer }}=2.0\right)$. 

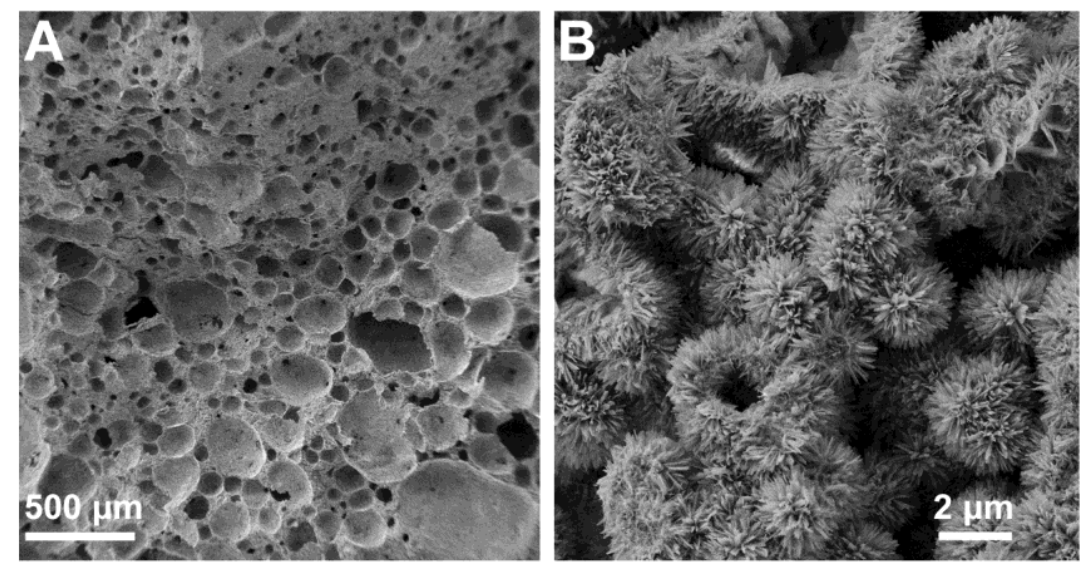

Fig. S5 (A) the SEM image of the fracture face of HPMC foamed CPCs $\left(\mathrm{L} / \mathrm{P}_{\text {total }}=0.8, \mathrm{~V}_{\text {air }} / \mathrm{V}_{\text {polymer }}=2.0\right)$; (B) the micro-morphology of cement matrix between macropores, showing needle-like crystal clusters.

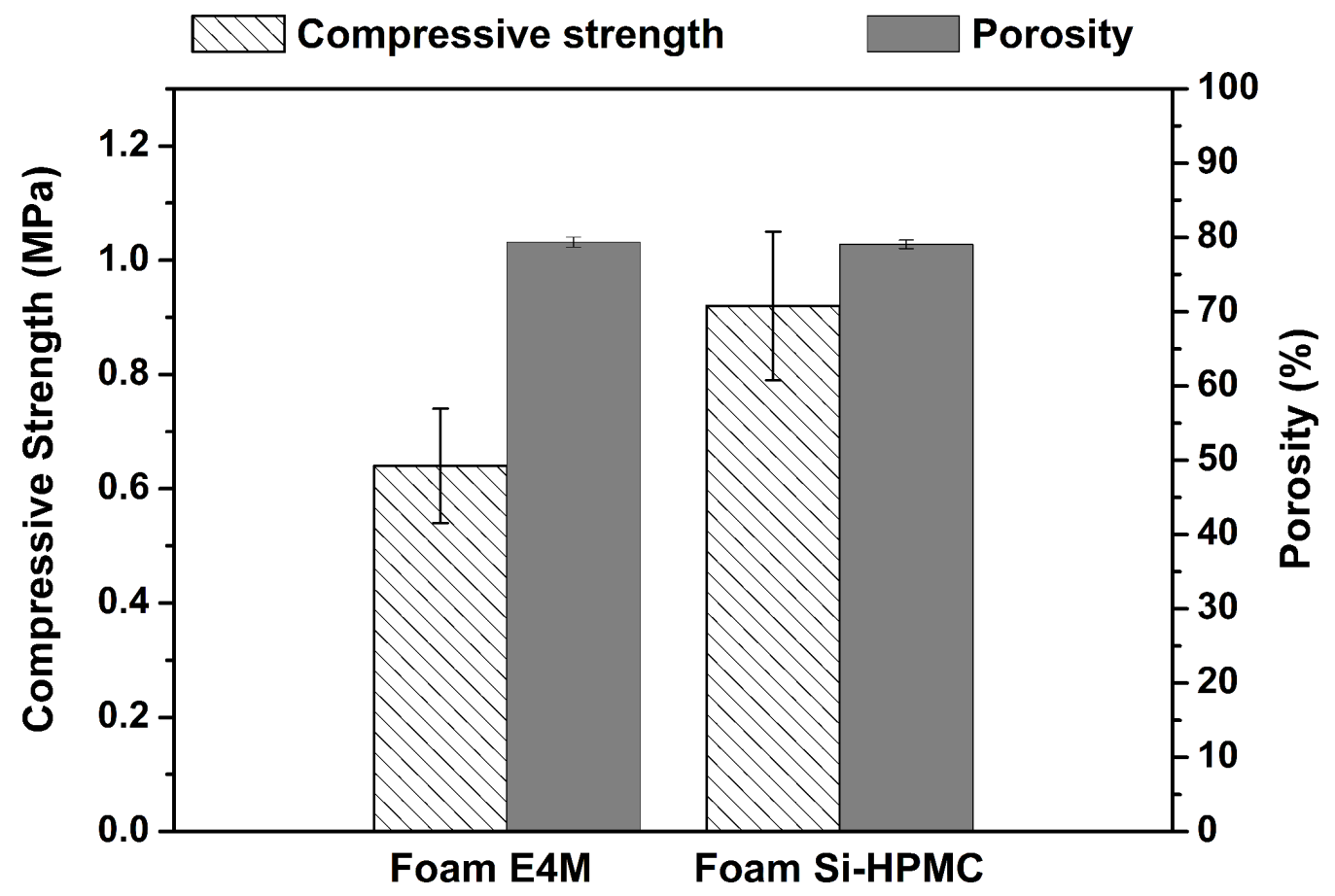

Fig. S6 The porosity and compressive strength comparison of foamed CPC with HPMC (E4M) and Si-HPMC. 


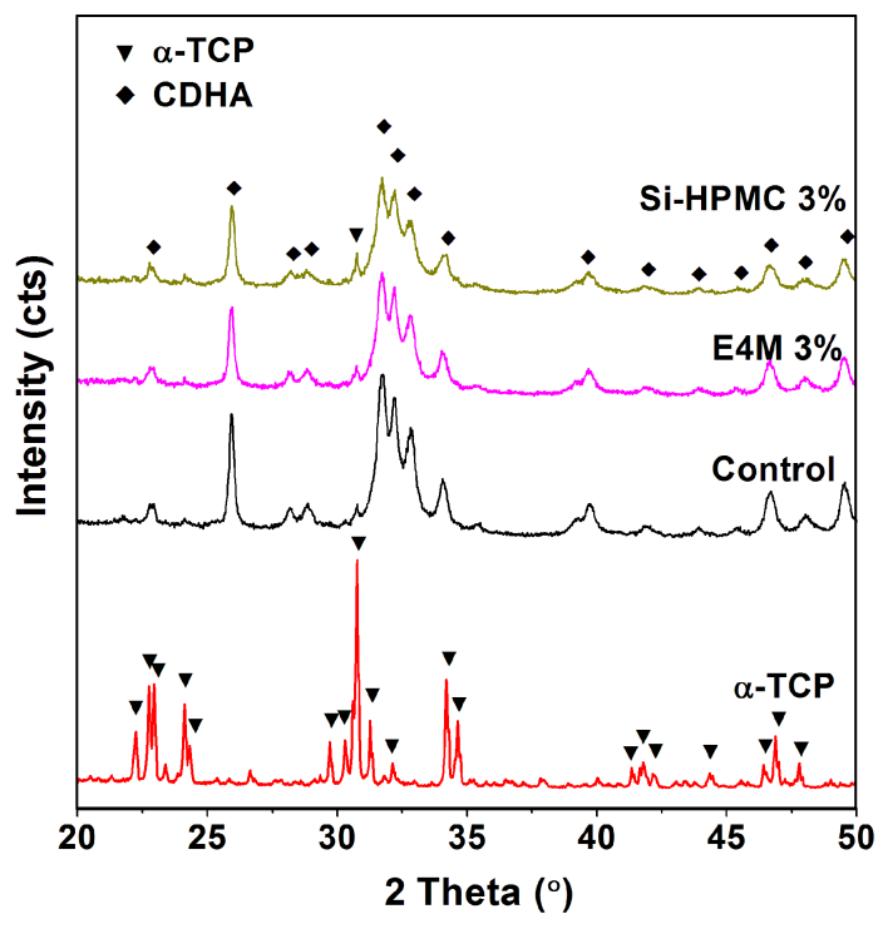

Fig. S7 XRD patterns of foamed CPC with Si-HPMC and HPMC (namely E4M).

\section{References:}

[1]. Chow, L.C. and S. Takagi, A natural bone cement - A laboratory novelty led to the development of revolutionary new biomaterials. JOURNAL OF RESEARCH OF THE NATIONAL INSTITUTE OF STANDARDS AND TECHNOLOGY, 2001. 106(6): p. 1029-1033.

[2]. Bohner, M., Physical and chemical aspects of calcium phosphates used in spinal surgery. EUROPEAN SPINE JOURNAL, 2001. 10: p. S114-S121.

[3]. Lewis, G., Injectable bone cements for use in vertebroplasty and kyphoplasty: State-of-the-art review. J Biomed Mater Res B Appl Biomater, 2006. 76B(2): p. 456-468.

[4]. Ginebra, M.P., et al., New processing approaches in calcium phosphate cements and their applications in regenerative medicine. Acta Biomater, 2010. 6(8): p. 2863-2873.

[5]. Ooms, E.M., et al., Histological evaluation of the bone response to calcium phosphate cement implanted in cortical bone. BIOMATERIALS, 2003. 24(6): p. 989-1000.

[6]. Ambard, A.J. and L. Mueninghoff, Calcium Phosphate Cement: Review of Mechanical and Biological Properties. Journal of Prosthodontics, 2006. 15(5): p. 321-328.

[7]. Dorozhkin, S.V., Calcium orthophosphate cements for biomedical application. JOURNAL OF MATERIALS SCIENCE, 2008. 43(9): p. 3028-3057.

[8]. Espanol, M., et al., Intrinsic porosity of calcium phosphate cements and its significance for drug delivery and tissue engineering applications. ACTA BIOMATERIALIA, 2009. 5(7): p. 2752-2762.

[9]. Khairoun, I., et al., In vitro characterization and in vivo properties of a carbonated apatite bone cement. JOURNAL OF BIOMEDICAL MATERIALS RESEARCH, 2002. 60(4): p. 633-642.

[10]. Ooms, E.M., et al., Trabecular bone response to injectable calcium phosphate (Ca-P) cement. JOURNAL OF BIOMEDICAL MATERIALS RESEARCH, 2002. 61(1): p. 9-18. 
[11]. Apelt, D., et al., In vivo behavior of three different injectable hydraulic calcium phosphate cements. Biomaterials, 2004. 25(7 - 8): p. 1439-1451.

[12]. Bouler, J.M., et al., Macroporous biphasic calcium phosphate ceramics: Influence of five synthesis parameters on compressive strength. JOURNAL OF BIOMEDICAL MATERIALS RESEARCH, 1996. 32(4): p. 603-609.

[13]. Ozgür Engin, N. and A.C. Tas, Manufacture of macroporous calcium hydroxyapatite bioceramics. Journal of the European Ceramic Society, 1999. 19(13 - 14): p. 2569-2572.

[14]. Ramay, H.R. and M.Q. Zhang, Preparation of porous hydroxyapatite scaffolds by combination of the gel-casting and polymer sponge methods. BIOMATERIALS, 2003. 24(19): p. 3293-3302.

[15]. Taboas, J.M., et al., Indirect solid free form fabrication of local and global porous, biomimetic and composite 3D polymer-ceramic scaffolds. BIOMATERIALS, 2003. 24(1): p. 181-194.

[16]. Fellah, B.H. and P. Layrolle, Sol - gel synthesis and characterization of macroporous calcium phosphate bioceramics containing microporosity. Acta Biomaterialia, 2009. 5(2): p. 735-742.

[17]. Barralet, J.E., et al., Preparation of macroporous calcium phosphate cement tissue engineering scaffold. BIOMATERIALS, 2002. 23(15): p. 3063-3072.

[18]. Xu, H., E.F. Burguera and L.E. Carey, Strong, macroporous, and in situ-setting calcium phosphate cement-layered structures. BIOMATERIALS, 2007. 28(26): p. 3786-3796.

[19]. Del Real, R.P., et al., A new method to produce macropores in calcium phosphate cements. BIOMATERIALS, 2002. 23(PII S0142-9612(02)00101-117): p. 3673-3680.

[20]. Almirall, A., et al., Fabrication of low temperature macroporous hydroxyapatite scaffolds by foaming and hydrolysis of an alpha-TCP paste. BIOMATERIALS, 2004. 25(17): p. 3671-3680.

[21]. Sarda, S., et al., Influence of surfactant molecules as air-entraining agent for bone cement macroporosity. JOURNAL OF BIOMEDICAL MATERIALS RESEARCH PART A, 2003. 65A(2): p. 215-221.

[22]. Xu, H. and J.B. Quinn, Calcium phosphate cement containing resorbable fibers for short-term reinforcement and macroporosity. BIOMATERIALS, 2002. 23(1): p. 193-202.

[23]. Link, D.P., et al., Mechanical evaluation of implanted calcium phosphate cement incorporated with PLGA microparticles. BIOMATERIALS, 2006. 27(28): p. 4941-4947.

[24]. Habraken, W., et al., Introduction of gelatin microspheres into an injectable calcium phosphate cement. JOURNAL OF BIOMEDICAL MATERIALS RESEARCH PART A, 2008. 87A(3): p. 643-655.

[25]. Lee, G.S., et al., Direct deposited porous scaffolds of calcium phosphate cement with alginate for drug delivery and bone tissue engineering. ACTA BIOMATERIALIA, 2011. 7(8): p. 3178-3186.

[26]. Xu, H. and C.G. Simon, Self-hardening calcium phosphate cement-mesh composite: Reinforcement, macropores, and cell response. JOURNAL OF BIOMEDICAL MATERIALS RESEARCH PART A, 2004. 69A(2): p. 267-278.

[27]. Igawa, K., et al., Tailor-made tricalcium phosphate bone implant directly fabricated by a three-dimensional ink-jet printer. J Artif Organs, 2006. 9(4): p. 234-40.

[28]. Charriere, E., J. Lemaitre and P. Zysset, Hydroxyapatite cement scaffolds with controlled macroporosity: fabrication protocol and mechanical properties. BIOMATERIALS, 2003. 24(5): p. 809-817.

[29]. Ginebra, M., et al., Factors affecting the structure and properties of an injectable self-setting calcium phosphate foam. Journal of Biomedical Materials Research Part A, 2007. 80(2): p. 351-361.

[30]. Montufar, E.B., et al., Foamed surfactant solution as a template for self-setting injectable hydroxyapatite scaffolds for bone regeneration. Acta Biomaterialia, 2010. 6(3): p. 876-885.

[31]. Montufar, E., et al., Self-hardening calcium deficient hydroxyapatite/gelatine foams for bone regeneration. Journal of Materials Science: Materials in Medicine, 2010. 21(3): p. 863-869.

[32]. Perut, F., et al., Novel soybean/gelatine-based bioactive and injectable hydroxyapatite foam: Material properties and cell response. Acta Biomaterialia, 2011. 7(4): p. 1780-1787. 
[33]. Liu, W., et al., The influence of different cellulose ethers on both the handling and mechanical properties of calcium phosphate cements for bone substitution. Acta Biomater, 2013. 9(3): p. 5740-50.

[34]. Liu, W., et al., A novel injectable, cohesive and toughened Si-HPMC (silanized-hydroxypropyl methylcellulose) composite calcium phosphate cement for bone substitution. Acta Biomater, 2014. 10(7): p. 3335-45.

[35]. Xu, H.H.K. and C.G. Simon Jr, Fast setting calcium phosphate - chitosan scaffold: mechanical properties and biocompatibility. Biomaterials, 2005. 26(12): p. 1337-1348.

[36]. Gauthier, O., et al., Macroporous biphasic calcium phosphate ceramics: influence of macropore diameter and macroporosity percentage on bone ingrowth. BIOMATERIALS, 1998. 19(1-3): p. 133-139.

[37]. Gauthier, O., et al., Macroporous biphasic calcium phosphate ceramics versus injectable bone substitute: a comparative study 3 and 8 weeks after implantation in rabbit bone. JOURNAL OF MATERIALS SCIENCE-MATERIALS IN MEDICINE, 2001. 12(5): p. 385-390.

[38]. Gauthier, O., et al., In vivo bone regeneration with injectable calcium phosphate biomaterial: A three-dimensional micro-computed tomographic, biomechanical and SEM study. Biomaterials, 2005. 26(27): p. 5444-5453.

[39]. Laib, S., et al., The in vivo degradation of a ruthenium labelled polysaccharide-based hydrogel for bone tissue engineering. BIOMATERIALS, 2009. 30(8): p. 1568-1577.

[40]. Fatimi, A., et al., The rheological properties of silated hydroxypropylmethylcellulose tissue engineering matrices. BIOMATERIALS, 2008. 29(5): p. 533-543.

[41]. Bourges, X., et al., Synthesis and general properties of silated-hydroxypropyl methylcellulose in prospect of biomedical use. ADVANCES IN COLLOID AND INTERFACE SCIENCE, 2002. 99(PII S0001-8686(02)00035-03): p. 215-228.

[42]. Fatimi, A., et al., Gelation studies of a cellulose-based biohydrogel: The influence of pH, temperature and sterilization. ACTA BIOMATERIALIA, 2009. 5(9): p. 3423-3432.

[43].Vinatier, C., et al., A silanized hydroxypropyl methylcellulose hydrogel for the three-dimensional culture of chondrocytes. BIOMATERIALS, 2005. 26(33): p. 6643-6651.

[44]. Trojani, C., et al., Three-dimensional culture and differentiation of human osteogenic cells in an injectable hydroxypropylmethylcellulose hydrogel. BIOMATERIALS, 2005. 26(27): p. 5509-5517.

[45]. Trojani, C., et al., Ectopic bone formation using an injectable biphasic calcium phosphate/Si-HPMC hydrogel composite loaded with undifferentiated bone marrow stromal cells. BIOMATERIALS, 2006. 27(17): p. 3256-3264.

[46]. Fellah, B.H., et al., Bone repair using a new injectable self-crosslinkable bone substitute. JOURNAL OF ORTHOPAEDIC RESEARCH, 2006. 24(4): p. 628-635.

[47]. Vinatier, C., et al., Engineering cartilage with human nasal chondrocytes and a silanized hydroxypropyl methylcellulose hydrogel. JOURNAL OF BIOMEDICAL MATERIALS RESEARCH PART A, 2007. 80A(1): p. 66-74.

[48]. Cherng, A., S. Takagi and L.C. Chow, Effects of hydroxypropyl methylcellulose and other gelling agents on the handling properties of calcium phosphate cement. JOURNAL OF BIOMEDICAL MATERIALS RESEARCH, 1997. 35(3): p. $273-277$.

[49]. Bohner, M. and G. Baroud, Injectability of calcium phosphate pastes. BIOMATERIALS, 2005. 26(13): p. 1553-1563.

[50]. Habib, M., et al., Mechanisms underlying the limited injectability of hydraulic calcium phosphate paste. ACTA BIOMATERIALIA, 2008. 4(5): p. 1465-1471.

[51]. Bohner, M., G. Baroud and B. Gasser, SnapShot: Critical aspects in the use of injectable calcium phosphates in spinal surgery. BIOMATERIALS, 2010. 31(16): p. 4609-4611.

[52]. Del Valle, S., et al., In vivo evaluation of an injectable Macroporous Calcium Phosphate Cement. JOURNAL OF MATERIALS SCIENCE-MATERIALS IN MEDICINE, 2007. 18(2): p. 353-361.

[53]. Flautre, B., et al., Porous HA ceramic for bone replacement: role of the pores and interconnections - experimental study in the rabbit. J Mater Sci Mater Med, 2001. 12(8): p. 679-82.

[54]. Fu, Q., et al., Bioactive glass scaffolds for bone tissue engineering: state of the art and future perspectives. Materials Science and Engineering: C, 2011. 31(7): p. 1245-1256. 
[55]. Wagoner, J.A. and B.A. Herschler, A review of the mechanical behavior of $\mathrm{CaP}$ and CaP/polymer composites for applications in bone replacement and repair. Acta Biomater, 2011. 7(1): p. 16-30.

[56]. Frankenburg, E.P., et al., Biomechanical and histological evaluation of a calcium phosphate cement. JOURNAL OF BONE AND JOINT SURGERY-AMERICAN VOLUME, 1998. 80A(8): p. 1112-1124.

[57]. Kurashina, K., et al., In vivo study of calcium phosphate cements: Implantation of an alpha-tricalcium phosphate dicalcium phosphate dibasic tetracalcium phosphate monoxide cement paste. BIOMATERIALS, 1997. 18(7): p. 539-543.

[58]. Sohier, J., et al., Hydrogel/calcium phosphate composites require specific properties for three-dimensional culture of human bone mesenchymal cells. ACTA BIOMATERIALIA, 2010. 6(8): p. 2932-2939.

[59]. Rederstorff, E., et al., An in vitro study of two GAG-like marine polysaccharides incorporated into injectable hydrogels for bone and cartilage tissue engineering. ACTA BIOMATERIALIA, 2011. 7(5): p. 2119-2130.

[60]. Gauthier, O., et al., Short-term effects of mineral particle sizes on cellular degradation activity after implantation of injectable calcium phosphate biomaterials and the consequences for bone substitution. BONE, 1999. 25S(2): p. 71S-74S.

[61]. Daculsi, G., et al., Biphasic calcium phosphate/hydrosoluble polymer composites: A new concept for bone and dental substitution biomaterials. BONE, 1999. 25S(2): p. 59S-61S.

[62]. Weiss, P., et al., The safety and efficacy of an injectable bone substitute in dental sockets demonstrated in a human clinical trial. BIOMATERIALS, 2007. 28(22): p. 3295-3305. 